\title{
REALIDAD JURÍDICO-SOCIAL DE LA CONQUISTA ROMANA DE HISPANIA
}

\section{María José Bravo Bosch}

Profesora-titular de Direito Romano da Universidade de Vigo (Espanha) bravobosch@uvigo.es

\begin{abstract}
Resumen: Desde el análisis de los motivos que condujeron a los romanos a conquistar nuestro territorio, hasta un recorrido político - social sobre la organización romana trasladada a suelo hispano, incidiendo en la evolución del concepto de provincia. Finalmente, traemos a colación la importancia de las leyes municipales, para detenernos en la concesión del ius latii por parte del emperador Vespasiano.
\end{abstract}

Palabras clave: Provincia. Hispania. Municipio. Ius latii.

Resulta necesario explicar antes de nada que nuestro interés en la conquista romana de Hispania no persigue un recorrido única y exclusivamente referido al Derecho Romano presente en esta etapa histórica, por entender que un análisis multidisciplinar ${ }^{1}$ resulta mucho más completo a la hora de acometer un estudio sobre la Hispania Romana.

Por todo ello, es a la luz de elementos históricos, políticos, sociales y de carácter administrativo como hemos procedido a presentar los largos siglos de conquista $^{2}$ del territorio de Hispania, hasta detenernos en la concesión del ius latii por parte del Emperador Vespasiano ${ }^{3}$

\footnotetext{
1 Vid. al respecto, CROOK, Law and life of Rome, Londres, 1967, p. 7, en donde refiere la importancia del análisis realizado desde distintos puntos de vista, cuando habla de su propio libro: "This is not quite a book about Roman law, on which there already exist any number of excellent treatises. Neither is it quite a book about Roman social and economic life; that subject, too, is already illuminated by massive works of scholarship. It is about Roman law in its social context, an attempt to strengthen the bridge between two spheres of discourse about ancient Rome by using the institutions of the law to enlarge understanding of the society and bringing the evidence of the social and economic facts to bear on the rules of the law".

2 Motivada, según algunos autores por el afán imperialista, mientra que otros sostienen que una política defensiva con respecto al avance de los cartagineses es la principal razón de la conquista de Hispania por parte de los romanos. A lo largo de estas páginas ponemos en evidencia ambas teorías, apostando por una primera presencia militar con carácter defensivo, que después perseguirá las múltiples riquezas del territorio hispánico.

3 En lo que se refiere al acto concreto de concesión, declara SHERWIN-WHITE, The Roman Citizenship, Oxford, 1973, p. 252: "The Flavians complete the work of centuries in Spain.'Universae Hispaniae Vespasianus imperator... Latium tribuit'. This is the machine at work; a short passage of Pliny seems to reproduce its regulated beat: 'Oppidum ... Caesarea... a divo Claudio coloniae iure donata; eiusdem iussu deductis veteranis oppidum Novum et Latio dato Tipasa, itemque a Vespasiano imperatore eodem munere donatum Icosium"”, añadiendo poco después: "The activity of the Flavians was not confined to Spain".
} 
La Península Ibérica, antes de marzo de 218 a.C. ${ }^{4}$, fecha en la que el Senado asigna por primera vez Hispania como provincia ${ }^{5}$, no era una desconocida para los romanos. Con todo, el conocimiento sobre la realidad de la misma era escaso, demostrando mayor empeño en conocer a los pueblos colonizadores ${ }^{6}$-primero los fenicios ${ }^{7}$ y luego sus sucesores los cartagineses ${ }^{8}$, así como los griegos ${ }^{9}$ - que a los moradores ${ }^{10}$ de la península desde antiguo ${ }^{11}$. De este modo, la Iberia así

4 Sobre la fecha, RICH, Declaring war in the Roman republic in the period of transmarine expansion, Bruselas, 1976, p. 28-44.

5 Livio, 21, 17, 1.

6 Vid. acerca de las relaciones entre colonizadores e íberos, HARRISON, Spain at the Dawn of History, Londres, 1988, passim.

7 Cfr. RICHARDSON, The Romans in Spain, Oxford, 1996, p. 13-14: "Whatever else linked the Iberian peoples together, it is clear that they all experienced the impact of the two great colonization movements of the Phoenicians and the Greeks in the ninth to the sixth centuries BC. The Phoenicians had been the first to arrive in the west, and had already established Carthage in north Africa in the late ninth or eighth century BC. At about the same time, they began to plant colonies in Spain, especially at Cádiz (the Phoenician Gadir, and subsequently the Roman Gades), which was well placed to draw on the rich minerals traded by the Tartessians. Chief among these was the silver of the Sierra Morena, drawn from the mines around the Rio Tinto and perhaps also from the mining region round Linares in the upper valley of the Guadalquivir. The other area of Phoenician settlement was on the south coast of Andalusia, where the ancient sources record sites at Malaca (now Málaga), Sexi (Almuñecar) and Abdera (Adra), of which the last two have produced archeological evidence of a Phoenician presence. Other colonies are known from archeological investigation at a number of other sites in the same area, including Toscanos and Trayamar".

8 BARCELÓ, Karthago und die iberische Halbinsel vor den Barkiden, Bonn, 1988, passim, en donde afirma que el interés de los cartagineses por nuestro territorio procedía de las posibilidades para el comercio y como fuente de soldados mercenarios; esto en un primer momento, pero posteriormente los cartagineses tienen clara la importancia hispana como base para sus operaciones militares y expansionistas; así, BLÁZQUEZ, en un artículo anterior al señalado, "Relaciones marítimas entre Hispania y las regiones del Mediterráneo durante la república romana”, en Studi in onore di Giuseppe Grosso 2, Turín, 1968, p. 171, afirma: "Cádiz se menciona como base naval de los cartagineses en las campañas púnicas de reconquista de la Península Ibérica, efectuadas por Amilcar a partir del año 237 a. C. Precisamente en este puerto fue donde desembarcó el ejército expedicionario", remitiéndonos a Polibio, 2, 1, 5, quien señala de forma clara a Cádiz como apoyo para el ejercito cartaginés; sobre el puerto de Cádiz, vid. por todos, GARCÍA Y BELLIDO, Fenicios y carthagineses en Occidente, Madrid, 1942, p. 49 ss.; "Iocosae Gades", en BRAH 129, 1951, p. 73 ss.; Historia de España, I, 2, Madrid, 1952, p. 316 ss. 389 ss.

9 Vid. sobre la presencia de los griegos, posterior a la fenicia y ubicada en lugares diferentes: GARCIA BELLIDO, Hispania Graeca, Barcelona, 1948, passim; más actual, KEAY, Roman Spain, Londres, 1988, p. 14: "After the mid-sixth century Greek colonists ... founded colonies at Rhode (modern Roses), Emporion (modern Empuries) Hemeroskopeion (modern Denia) and Mainake (near Málaga), using the primary colony of Massalia (modern Marseilles) as their base... Moreover, their presence had a profound effect on the native Iberian communities with whom they traded. Greek influence spread extensively and is evident in many aspects of their culture"; interesante aclaración la de FERNÁNDEZ DE BUJÁN, A., "Observaciones a propósito del tránsito de la Iberia-griega y púnica a la Hispania romana", en RGDR 2, 2004, p. 7: “... si bien parece probable que fueron los navegantes griegos los primeros que llegaron a las costas peninsulares, los primeros asentamientos estables corresponderían a los fenicios".

${ }^{10}$ Str. 3, 4, 19, en donde refiere las dificultades para hablar de los pueblos de la Península Ibérica, debido al pequeño tamaño de las unidades en las que estaban divididos, y a la escasa capacidad de los autores griegos y latinos que le precedieron - Estrabón es ya de la época de Augusto y Tiberio, finales del siglo I. a. C y principio del s. I. d. C- para llevar tal tarea a buen término

${ }^{11}$ Pudiendo citar, dentro de la Iberia Prerromana: los calaicos, los astures, los cántabros, los vascones, los ceretanos, los indicetes, ausetanos, layetanos, cesetanos, ilergetes, celtíberos, arévacos, vacceos, lusones, 
denominada por los griegos ${ }^{12}$, suscitaba interés en un primer momento por su especial posición geográfica ${ }^{13}$, entre el oceáno atlántico y el mar mediterráneo (mare nostrum) y sus posibilidades como punto estratégico frente a posibles guerras o invasiones. Siguiendo a KEAY ${ }^{14}$ : "Iberia is the largest peninsula (580.160 square kilometres) in Europe and comprises many geographically distinct areas; it also occupies a unique position separating the Atlantic from the Mediterranean and Europe from Africa. This explains why Iberia has always been a country of passage, contact and confrontation between invaders and native peoples".

La preocupación romana ante la expansión de los cartagineses es la que conduce en un primer momento a los Romanos ${ }^{15}$ a Iberia, y no creemos que las riquezas existentes en Hispania ${ }^{16}$ que se aducen como motivo del desembarco de los romanos en nuestro territorio- sean la razón de la decisión adoptada por el Senado en marzo de 218 a. C.

belos, titios, edetanos, ilergaones, carpetanos, vetones, lusitanos, celtas, conios, turdetanos, oretanos, bastetanos, contestanos; sobre la España prerromana, ARNOLD, The Roman System of Provincial Administration to the Accession of Constantine the Great, $3^{\mathrm{a}}$ ed. (ed. anastática) Roma, 1968, cuando después de referirse a la Galia, declara en p. 36: "We are not equally familiar with pre-Roman Spain; but some of the same points come out clearly. Just as in Gaul, the different tribes were continually at war; and the necessity of constant preparation for self-defence made agriculture impossible, and neutralised the natural fertility of the country"; sobre los núcleos indígenas del Sur, ROLDÁN HERVÁS, "Conquista y colonización de la Bética en época republicana”, en Teoría y práctica del ordenamiento municipal en Hispania, Revisiones de Historia Antigua II, Vitoria, 1996, p. 29: “Así pues, desarrollo desigual y heterogeneidad en cuanto a principios organizativos, carácter de la propiedad y estructuras sociales, constituyen las premisas de las que hay que partir a la hora de analizar la transformación de las estructuras indígenas, que comienzan con la propia conquista romana desde que Escipión desembarca en Ampurias en 218"; al objeto de profundizar en esta etapa histórica, FERNÁNDEZ CASTRO, La prehistoria de la península ibérica, Barcelona, 1997, passim.

12 Vid. al respecto, RICHARDSON, The Romans in Spain, cit. p. 2: "For the Greeks, who established settlements on the Mediterranean coastline in Catalunya, and perhaps further south also, from the sixth century BC onwards, the name they gave it (Iberia) carried with it no notion of a national or administrative whole", recordando que el geográfo griego Estrabón, apuntaba que el nombre se le había dado a varias zonas distintas; cfr. Str. 4, 4, 19.

${ }^{13}$ Sobre la geografía de la Península Ibérica, vid. SCHULTEN, Iberischen Landeskunde 2 vol. , Estrasburgo, 1955-1957; WAY\&SIMMONS, A geography of Spain and Portugal, Londres, 1962; TOVAR, Iberische Landeskunde: Die Völker und Städte des antiken Hispanien, Baden-Baden, 1974-1989.

${ }^{14}$ Roman Spain, cit., p. 8.

${ }^{15}$ Cfr. RICHARDSON, Hispania y los Romanos, trad. esp. Barcelona, 1998, p. 40: "El primer interés que mostró Roma por la península ibérica no sería fruto de su atracción por el propio país, ni siquiera por sus recursos naturales o por sus habitantes. Los romanos se volcaron sobre Hispania debido a la presencia en ella de los cartagineses, y en particular de la familia de los Bárcidas".

${ }^{16}$ Cfr. HARRIS, War and imperialism in republican Rome 327-70 BC, Oxford, 1979, p. 205: "Spain in particular was probably regarded by Roman senators as a rich prize that could be won in a war against Carthage"; en apoyo de esta teoría imperialista, PINA POLO, "Imperialismo y estrategia militar en la conquista de Hispania Citerior (218-153 a. C.), en Segeda y su contexto histórico. Entre Catón y Nobilior (195 al 153 a. C.), Zaragoza, 2006, p. 71: “Mientras en el Mediterráneo oriental el Estado romano actuó con cautela y prudencia, pasando en medio siglo del inicial intervencionismo a la imposición de su hegemonía y, sólo finalmente a la anexión territorial, en la Península Ibérica se condujo prácticamente desde su desembarco en Emporion en el año 218 como una potencia imperialista... En mi opinión, la 
En apoyo de esta tesis, RICHARDSON ${ }^{17}$ afirma: "Spain as an area of explotation, political or economic, seems to have been a secondary concern, compared with the presence of an expanding and potentially hostile Carthaginian dominion". De la misma opinión, KEAY ${ }^{18}$ : "Rome's conquest of Iberia was the direct result of an epic power struggle with her old North African rival, Carthage, to control the western Mediterranean ${ }^{19}$ ". A mayor abundamiento, señala SALINAS DE FRÍAS ${ }^{20}$ : "En el año 218 a. C., en previsión de la guerra contra Aníbal, el Senado ${ }^{21}$ asignó a los cónsules como provinciae las de Hispania y Africa y Sicilia ${ }^{22 "}$, correspondiéndole mediante sorteo Hispania a Publio Escipión y la provincia de Africa y Sicilia a Tiberio Sempronio Longo ${ }^{23}$. Con rotundidad se expresa ROLDÁN HERVÁS ${ }^{24}$, cuando afirma: "La necesidad de sustraer a Cartago

permanencia de Roma en Hispania no fue la consecuencia no planeada a priori de la victoria sobre Cartago, como se suele afirmar" concluyendo que la voluntad del Estado romano era la de establecer un dominio permanente en Hispania, seguida de una "política de anexión y explotación económica del territorio que había estado presente desde el primer momento".

${ }^{17}$ Hispaniae. Spain and the development of Roman imperialism, 218-82 BC, Cambridge, 1986, p. 30, en donde se refiere particularmente a la intervención en Hispania de la siguiente forma: "In the particular case of Spain, however, there is little sign that they were of much weight in shaping the actions of the senate. The possibility of rich prizes will not have been ignored, but on all the occasions when the Romans took any action, and specially over the Ebro treaty with Hasdrubal in 226, the major consideration seems to have been the possibility of war, and the importance of ensuring that when hostilities broke out, they did so at a time and in circumstances that were most favourable to the Romans".

${ }^{18}$ Roman Spain, cit. p. 25.

${ }^{19}$ Hay que insistir en la idea de que el motivo del enfrentamiento continuo entre Cartago y Roma (las guerras púnicas) es que las dos pugnaron siempre por el liderazgo en el Mediterráneo occidental. Así, afirma MANGAS, Historia Universal. Edad Antigua. Roma, Barcelona, reimp. 2001, p. 102: "Nosotros sostenemos con otros muchos que la guerra era inevitable desde el momento en que tanto Roma como Cartago llevaban una política destinada al mismo objetivo de ser la única potencia hegemónica del Mediterráneo occidental y con los mismos métodos".

${ }^{20}$ El gobierno de las provincias hispanas durante la república romana (218-27 A.C), Salamanca, 1995, p. 23.

${ }^{21}$ RICHARDSON, Hispaniae, cit. p. 31: "It is no difficult to see why Spain seemed important to the senate. First, and most importantly, it was where Hannibal and his army were, and therefore where it was expected that the war would actually take place, when the embassy bearing the final ultimatum left for Carthage once the consular commands had been assigned"; cfr. Livio 21, 18, 1; Polibio, 3, $20,6$.

${ }^{22}$ Vid. al respecto, LUZZATTO, Roma e le province I. Organizzazione, Economia, Società, Bolonia, 1985, p. 47: "Il primo territorio organizzato a provincia è la Sicilia. Il trattato di pace del 241 a. C. con Cartagine obbbligava quest'ultima ad evacuare la Sicilia, Lipari e le Egadi, oltre al pagamento di 3200 talenti in 10 anni e all'obbligo di rispettare Siracusa e i suoi alleati. Nel 237 l'isola veniva formalmente annessa come provincia: rimaneva indipendente una ristretta fascia orientale, comprendente Siracusa e sei citta soggette alla sovranità di quest'ultima (Heloros, Nector, Akrai, Megara, Leontini, Tauromenium). Messina, la causa occasionale della guerra, conservava, come conseguenza della deditio in fidem al popolo romano, la condizione di città federata".

${ }^{23}$ Cfr. Livio 21, 17, 1; Pol. 3, 40, 2.

${ }^{24}$ Historia Antigua de España I. Iberia prerromana, Hispania republicana y alto imperial, $2^{\mathrm{a}}$ ed. Madrid, 2005, p. 227, en donde añade que las dificultades estratégicas romanas en Hispania, por desconocimiento del país, escasez de legionarios y problemas de avituallamiento,"obligaron desde un principio a los responsables de la guerra en la Península a presentar su acción como un deseo de liberar los territorios controlados por Cartago de un yugo impuesto por la fuerza a los indígenas, identificando así sus objetivos con los de una gran mayoría de las propias tribus peninsulares, a las que no fue difícil atraer como aliados". 
una de sus fundamentales vía de recursos como medio de neutralizar la agresión de Aníbal sobre Italia ${ }^{25}$ fue el objetivo primero ${ }^{26}$ de las tropas romanas al convertir Iberia en escenario de guerra, ajeno a cualquier voluntad de conquista".

Lo cierto es que la necesidad de frenar el avance de los rivales cartagineses es sin duda el motivo principal ${ }^{27}$ que provoca la decisión senatorial que supondrá una conquista ${ }^{28}$, la de Hispania, llena de esfuerzo desde un principio, con múltiples batallas, insurrecciones, actividades diplomáticas y decisiones administrativas, con una duración excesiva ${ }^{29}$ en el tiempo, pudiendo hablar de un periodo de casi 200 años ${ }^{30}$ de sucesivas campañas militares hasta conseguir la pacificación definitiva del territorio hispano. Como declara FERNÁNDEZ DE BUJÁN, A. ${ }^{31}$ : "Roma está pues presente durante seis siglos y medio en territorio peninsular: dos

${ }^{25}$ Como dice GOODFELLOW, Roman Citizenship, Lancaster, 1935, p. 20: "The Hannibalic War marks a change in the situation of the allies. It is true that Rome's victory had been possible only because of the remarkable loyalty of most Italian communities"; DAHLHEIM, Struktur und Entwicklung des römischen Völkerrechts im dritten und zweiten Jahrhundert v. Chr., Munich, 1968, p. 111: "Vor Beginn des Ersten Punischen Krieges hat sich -um mit TH. MOMMSEN zu sprechen- die italische Wehrgenossenschaft konsolidiert", destacando la importancia de la liga latina para la posterior hegemonía de Roma.

${ }^{26} \mathrm{Sin}$ olvidar que lógicamente, a medida que avanzaba la conquista, el ansia de botín fue mayor. Vid. como visión, de un modo general, sobre las perspectivas de una conquista, GRUEN, "Material rewards and the drive for Empire", en The Impérialism of mid-republican Rome, American Academy in Rome, 29, 1984, p. 59: "Conquest brought tangible benefits. The laws of war in antiquity assured and legitimized them. Expropriation of land, seizure of movable goods, imposition of monetary penalties, enslavement of the enemy went unquestioned as earned emoluments of the victor. Romans certainly never questioned them".

${ }^{27}$ Cfr. HOMO, L'Italie primitive et les débuts d l'imperialisme romain, París, 1925, p. 374, en donde afirma que la conquista de Hispania es un simple episodio de las guerras púnicas motivada por razones militares, no económicas, para cortar las bases de aprovisionamiento del ejército expedicionario cartaginés que estaba en Italia.

${ }^{28}$ LE ROUX, Romanos de España. Ciudades y política en las provincias [siglo II A. C.- siglo III D. C.], trad. esp. Barcelona, 2006, p. 42: "La originalidad de la historia de la conquista hispánica radica en que tuvo lugar en los inicios de la expansión romana fuera de Italia y las islas, y en que fue diferente, en cuanto a su contexto, a las otras conquistas occidentales".

${ }^{29}$ Vid. al respecto, ESCUDERO, Curso de Historia del Derecho, Madrid, 1995, p. 110: "Obviamente la Romanización fue un largo proceso, desigualmente asimilado por distintos países y, dentro de ellos, por los diversos territorios y pueblos, quienes al recibir el legado romano aportaron sus propios particularismos a ese gran sistema de signo eminentemente receptivo".

${ }^{30}$ Floro, 1, 33; ARNOLD, The Roman system of Provincial Administration, cit. p. 37: "On this account the Romans, having carried the war into Iberia, lost much time by reason of the number of different sovereignties, which they had to conquer one after another; in fact it was nearly two cwnturies, or even longer, before they had subdued the whole"; KEAY, Roman Spain, cit. p. 25: "The Roman conquest of Iberia is the compelling story of nearly 200 years of continuous military campaigns".

31 "Observaciones acerca del tránsito de la Iberia-griega", cit. p. 21, concretando el periodo de romanización ya en p. 20: "Se suele considerar de forma convencional el período de tiempo comprendido entre las fechas del 206 a. C., en el que tiene lugar el desembarco del ejército romano en Ampurias a fin de contrarrestar la ocupación cartaginesa, y el 446 d. C., año en el que el rey visigodo Eurico rompe de manera definitiva con la condición de monarca federado de Roma, que habían ostentado sus antecesores e inicia a todos los efectos el período de la historia de España denominado de la monarquía visigoda, el correspondiente a la conquista, colonización, romanización y provincialización del solar ibérico, que a partir de entonces se denomina hispánico por Roma”. 
correspondientes $^{32}$ a la conquista y pacificación y cuatro en los que se produce un proceso de integración en el aparato administrativo del Estado romano y de romanización política, cultural y jurídica ${ }^{33}$, y si bien la asimilación de la cultura latina acabó siendo relevante en el conjunto de la geografía peninsular y especialmente profunda en las costas mediterráneas, en el valle del Guadalquivir, en el valle del Ebro $^{34}$ y en la provincia Bética ${ }^{35}$, la prolongada y espinosa etapa de conquista" hace explicable para el autor el reflejo constante en fuentes literarias ${ }^{36}$ y jurídicas de la difícil tarea ${ }^{37}$ de someter a Hispania al dominio romano.

32 SYME, The provincial at Rome, Exeter, 1999, p. 53: "It is clear enough that Roman settlement in Spain had been early and intensive. Two centuries of warfare before the conquest of the peninsula was at last achieved demanded the continuous presence of legions".

${ }^{33}$ Cfr. MORALES RODRÍGUEZ, La municipalización flavia de la Bética, Granada, 2003, p. 17, cuando señala: "La conquista romana de la Península Ibérica distorsionó la realidad indígena. El posterior establecimiento de un modelo basado en la civitas, imprescindible para el organigrama imperial, provocó profundas transformaciones, que tuvieron su proyección en el ámbito jurídico".

${ }^{34}$ Sobre el impacto de la romanización en el valle del Ebro, SAYAS, "Conquista y colonización del valle del Ebro en época tardorrepublicana y Principado", en Teoría y práctica del ordenamiento municipal en Hispania, cit. p. 63-64: "La romanización no es sólo un fenómeno resultante de la aplicación de una política determinada e intencionada por parte del conquistador. Es, sobre todo, un proceso dinámico en el que las costumbres, las formas de vida, los sistemas de organización política y social y las formas de explotación y disfrute de la tierra de los indígenas se hacen compatibles, al comienzo, con aquellos del conquistador, para acabr, luego, siendo asumidos en lo romano... Pero no todas las tierras y gentes de la Península Ibérica contaban,. Previamente, con un alto grado de madurez y de evolución cultural que facilitase el rápido arraigo de los impulsos romanizadores... En este sentido la región del Valle del Ebro constituye un marco geográfico idóneo en el que la contemplación y valoración de las transformaciones que acompañaron a la conquista y los cambios que se originaron con el posterior establecimiento del dominio romano presentan una evidente disparidad".

${ }^{35}$ Vid. al respecto, ROLDÁN HERVÁS, "Conquista y colonización de la Bética", cit. p. 39, cuando a modo de conclusión afirma: "En cualquier caso, César sentó las líneas sobre las que se desenvolvería el programa colonizador de las provincias de Hispania a lo largo del Imperio, apenas rectificadas, si no es en una mayor ampliación, por Augusto, siguiendo precisamente las directrices del dictador. Los territorios situados fuera de la línea de colonización propuesta por César nunca llegarían a integrarse por completo en las formas de vida romanas y, con ello, la Península quedó para siempre enmarcada en dos ámbitos muy distintos: el colonizado romano de la Bética, con cuña lusitana, la costa oriental y el Valle del Ebro, por un lado; el sometido, simple fuente de explotación y mucho menos urbanizado, con el resto de la Península, por el otro", resaltando la región bética con respecto a los otros territorios hispanos, que será elevada al estado de derecho por Augusto al crear la provincia Baetica como provincia senatorial, y como una de las más romanizadas de todo el Imperio Romano.

${ }^{36}$ Strab. 3, 4, 5; Vell. 2, 90.

${ }^{37}$ Vid. al respecto, REID, The municipalities of the Roman Empire, Cambridge, 1913, p. 229: "The long, slow, laborious conquest of Spain placed a severe strain on the resources of the Roman Republic, and its completion was the severest task of Augustus during the early years of his ascendency". 
La presencia romana en España ${ }^{38}$ se inicia, por lo tanto, con el desembarco del ejército romano en Ampurias ${ }^{39}$ en otoño ${ }^{40}$ del año 218 a. C. ${ }^{41}$, siguiendo las instrucciones del Senado que habían asignado Hispania como provincia ${ }^{42}$ a Publio Escipión en marzo de ese mismo año ${ }^{43}$, quien -ante el rápido avance de Aníbal ${ }^{44}$ que suponía un grave peligro para Italia ${ }^{45}$ - decide unirse a las tropas destinadas en la Galia Cisalpina al mando del pretor Lucio Manlio, siendo su hermano Cneo quien se dirija con la mayor parte del ejército a Hispania ${ }^{46}$. La naturaleza

${ }^{38}$ Como consecuencia directa de la Segunda Guerra Púnica, que se desencadenó por el sitio a la ciudad de Sagunto (219-218), realizado por Aníbal (hijo de Amílcar). Sagunto no estaba protegida por el tratado de 226 (por su situación geográfica al sur del Ebro) pero había pedido auxilio a Roma, y como dice CURCHIN, España Romana, trad. esp. Madrid, 1996, p. 40:"La respuesta de Roma fue desmesuradamente tardía... Sólo cuando la ciudad cayó, Roma declaró la guerra a Cartago y organizó una expedición".

${ }^{39}$ Como introducción general, MARCET/ SANMARTÍ, Empúries, Barcelona, 1990; con respecto a su etimología, RICHARDSON, Hispania y los Romanos, cit. p. 21: "El propio nombre de la ciudad griega de Emporion significa «emplazamiento mercantil»"; recientemente, BURILLO MOZOTA, "Oppida y ciudades estado del Norte de Hispania", en Segeda y su contexto histórico, cit. p. 38: "Los focenses fundaron la colonia de Massalia hacia el 600 y estos massaliotas el puerto comercial de Emporion hacia el 575, sobre un antiguo asentamiento indígena... Emporion fue la primera ciudad que acuño monedas en toda la península Ibérica, a mediados del siglo V... En el año 219 los cartagineses atacan Saguntum. $\mathrm{Al}$ año siguiente, el ejército romano desembarca en Ampurias convirtiendo este oppidum, en cabeza de puente y el NE de la península en territorio aliado".

40 Aunque comúnmente aceptada tal estación del año como la del desembarco de las tropas romanas, vid. ROLDÁN HERVÁS, Historia Antigua de España, cit. p. 220: "Fue Emporion (Ampurias) la base del desembarco, que se realizó a fines del verano del 218 ".

${ }^{41}$ Vid. al respecto, BLÁZQUEZ, "Relaciones marítimas entre Hispania y las regiones del Mediterráneo", cit. p. 177: "Las principales bases navales de los romanos eran Ampurias (Pol. 3, 76) y Tarraco (Liv. 21, 61). En la primera ciudad desembarcaron los Escipiones en el año 218 a. C. La ciudad era colonia griega y aliada de Roma en la lucha contra Cartago (Pol. 3, 76; Liv. 21, 60). La primera escuadra romana que llegó acá fue precisamente destruida por Asdrúbal que la sorprendió descuidada en la costa".

${ }^{42}$ RICHARDSON, Hispaniae, cit. p. 31: "Spain, along with Africa-with-Sicily, the other provincia named at this time, were to be the places within which the consuls were meant to exercise their imperium. The naming of these provinciae was a essential step in the prosecution of the war, not a territorial claim

${ }^{43}$ RICHARDSON, The Romans in Spain, cit. p. 9: "When the Roman senate first assigned Hispania as a provincia in March 218 B.C....".

${ }^{44}$ Sobre la figura de Aníbal, y una descripción detallada de la segunda guerra púnica: LAZENBY, Hannibal's War, Warminster, 1978, passim.

${ }^{45}$ Incluido el retraso forzado por el reclutamiento de tropas y por tener que sofocar los ataques de los galos a las colonias latinas del norte de Italia; Polibio 3, 40; Livio 21, 25, 1-26, 4.

${ }^{46}$ Cfr. Polibio 3, 41, 4-8; 3, 49, 1-4; Livio 21, 26, 3-5; 21, 32, 1-5; según PINA POLO, "Imperialismo y estrategia militar en la conquista de Hispania Citerior", cit. p. 72: "En la práctica, el primer gran objetivo del ejército romano que desembarcó en Emporion en el año 218 fue restablecer la frontera fijada en el año 226", es decir, en el llamado "tratado del Ebro" firmado por el Estado romano con Asdrúbal en representación de Cartago, en el que se señalaba un límite septentrional al avance cartaginés en la Península Ibérica, identificado probablemente con el río Ebro (Iber) de acuerdo con Polibio 2, 13, 7, Livio 21, 2, 7 , y Apiano, Iber. 7, que fue transgredido por los cartagineses, llegando a afirmar en p. 71: "En realidad, el llamado "tratado del Ebro" del año 226 debe ser visto ya, desde mi punto de vista, como un claro anuncio de la voluntad anexionista de Roma en Hispania", tesis que consideramos alejada de la realidad de aquel momento histórico. 
del mandato recibido por Cneo escipión no está claro, ya que mientras unos, como RICHARDSON ${ }^{47}$, lo consideran un imperium pro praetore, otros, como JASHEMSKI $^{48}$ o SALINAS DE FRÍAS ${ }^{49}$, estiman que Cneo fue considerado un legatus pro consule ${ }^{50}$, siendo él mismo un privatus cum imperio.

En este momento histórico, no podemos inferir el significado de dicho término como equivalente al de una circunscripción territorial determinada, concepto más evolucionado que se implantará posteriormente ${ }^{51}$. En una primera etapa su acepción original debe entenderse como un encargo a un magistrado cum imperio ${ }^{52}$, y el conjunto de competencias otorgadas al mismo, como elementos sustanciales del término provincia. Sobre la evolución ${ }^{53}$ del significado de provincia se pronuncia LUZZATTO $^{54}$, aclarando su primera y primaria concepción: "Esso indicava infatti originariamente la sfera di competenza esclusiva di un magistrato ${ }^{55}$, sia in Italia che fuori. È in tal senso che le fonti ci parlano p. es. di una provincia Samnium o Etruria, oppure di una provincia urbana o peregrina $^{56}$ per designare rispettivamente la sfera di competenza del pretore urbano o peregrino ${ }^{57 "}$. Como apoyo argumental

${ }^{47}$ The Romans in Spain, cit. p. 36: "Throughout the period from 218 to 206 the senate seems to have allocated the single provincia of Hispania to a single consular or proconsular commander, with the exceptions of the disastrous joint command of the Scipio brothers in 212/211 and the sending of C. Nero pro praetore in the latter part of $211 "$.

48 The origins and history of the proconsular and the propraetorian imperium to 27 B.C., Roma, 1966, p. $22-24$.

${ }^{49}$ El gobierno de las provincias hispanas, cit. p. 24, en donde destaca varios hechos a favor de esta hipótesis: $1^{\circ}$, que su hermano Publio le confió el ejército consular, "y cuando al año siguiente éste fue destinado a Hispania como procónsul, Cneo no depuso su actividad sino que compartió con él el imperium". $2^{\circ}$, que en el 216 ambos hermanos se repartieron las fuerzas, quedando Cneo al mando de las de tierra y Publio con las de mar. $3^{\circ}$, Livio 25, 32, 1, llama a los dos imperatores (Mommsen creía que esto era un error, pero explicable porque en el año 212 el senado al dicidir Hispania en dos provincias, había asignado cada una a uno de los dos hermanos). Si Publio Escipión era desde el 217 procónsul y ahora su hermano estaba en la misma posición, "hay que concluir que el imperium de Cneo Escipión era proconsular y, puesto que desde el 222 en que había ejercido el consulado no había vuelto a ocupar otra magistratura, jurídicamente él era un privatus".

${ }^{50}$ Como su hermano Publio, que tenía el título de procónsul, en palabras de ROLDÁN HERVÁS, Historia Antigua de España, cit. p. 220.

${ }^{51}$ Vid. al respecto, Thesaurus 1.1. 10, 2, fasc. 15, col. 2332, en cuanto a su significado de origine: Pavl. Fest. p. 226 provinciae appellantur, quod populus Romanus eas provicit, id est ante vicit.

52 Oxford Latin Dictionary, Oxford, 1968, p. 1506, s.v. provincia ae: "1. The special function or task assigned to a magistrate, originally one holding imperium".

${ }^{53}$ Vid. al respecto, HERMON, "L'importance de la titulature des gouverneurs provinciaux pour le concept d'Empire pendant la République “, en IVRA 34, 1983, p. 75 : « Du même coup on est mis devant l'evidence de l'evolution du concept de provincia qui échappa au cadre normatif des institutions annuelles, tel qu'il se dessina aux débuts de l'administration provinciale, évolution qui étoffa et diversifia le pouvoir des hommes en vertu de leur imperium. Il s'agit en fait d'un rapport de dépendance provincia-imperium qui reste à l'origine de l'empirisme du moins apparent du gouvernement provincial derrière lequel pourrait se cacher un système concptuel cohérent ».

${ }^{54}$ Roma e le Province, I, cit., p. 26.

${ }_{55}^{5}$ De la misma opinión, SALINAS DE FRÍAS, El gobierno de las provinicas hispanas, cit. p. 23.

${ }^{56}$ Cic. Pro Murena 20, 42; Livio 39, 45.

${ }^{57}$ Vid. al respecto, DAUBE, "The peregrine Praetor", en JRS 41, 1-2, 1951, p. 67: "Then the peregrine 
nos ofrece los siguientes ejemplos que demuestran la imprecisión originaria ${ }^{58} \mathrm{del}$ término provincia: "Una conferma del significato originario della provincia, intesa come sfera di competenza generica, e insieme dell'incertezza della definizione di essa, ci è data dai ripetuti episodi di magistrati che esorbitavano dai propri limiti interferendo nelle sfere dei colleghi ${ }^{59}$. Tale il caso di Cn. Manlio Vulsone, che nel 189 attaccò i Galati di propria iniziativa e poté chiedere il trionfo; o di M. Popilio Lenate, che nel 173 mosse arbitrariamente guerra agli Stazielli, o di Appio Claudio Pulcro, che nel 143 attaccò senza autorizzazione i Salassi”.

Sólo con el tiempo asistiremos al cambio de la acepción de provincia como esfera de competencia de un magistrado, para identificar tal término con el territorio ${ }^{60}$ en el cual se ejerce dicha competencia, que es la acepción comunmente aceptada y así identificada por todos ${ }^{61}$. Para LUZZATTO ${ }^{62}$ estamos ante una etapa de incertidumbre en cuanto al significado de provincia, y en todo lo que concierne

praetorship was established, at a time when Rome acquired, or was about to acquire, the first provinces, Sicily and Sardinia... But the Romans of the third century B.C. were no doctrinaires. It would not be surprising if, for the time being, they had left the urban praetor in undisturbed exercise of jurisdiction where a peregrine sued, or was sued by, a citizen. We have argued above that quite probably this is what they did".

${ }^{58}$ HERMON, "L'importance de la titulature des gouverneurs provinciaux", cit. p. 77 : « A partir de 241 avec la création de la province de Sicile, la double nature de la provincia -sphère d'action militaire et district territorial permanent- influença sur la nature de l'imperium des magistrats et des promagistrats en opérant une distinction précise de leur tâche. En fait, en 227, avec la création des nouveaux préteurs assignés aux deux districts territoriaux existant alors -la Sicile et la Sardegne- la magistrature annuelle de préteur fut assignée à l'administration de ces territoires. La signification de l'acte de 227 semble évidente : seul l'imperium d'un préteur est associé à l'acception territoriale de la provincia tandis que l'imperium consulaire ert celui de la promagistrature en général restent associés à son acception militaire. Cette distinction entre les divers imperia est d'ailleurs confirmée par la pratique assez régulière d'assigner ces deux territoires à des préteurs annuels ».

${ }^{59}$ Cfr. RICHARDSON, Hispania y los romanos, cit. p. 54-55, en donde expone de forma detallada numerosos casos de magistrados que no respetaron los límites provinciales, por diversos motivos, principalmente bélicos.

${ }^{60}$ Oxford Latin Dictionary, cit. p. 1506, s. v. provincia ae, como tercer significado del término: "A territory outside Italy under the direct administration of a governor from Rome, a province"; Th. L. 1. cit. col. 2334, en cuanto al significado metonímico, dice en su apartado II: de imperii Romani partibus (sc. Inde a Sicilia capta) ita constitutis, ut in perpetuum a magistratu Romano regerentur.

${ }^{61}$ Vid. al respecto, RICHARDSON, "The administration of the Empire", en The Cambridge Ancient History, $2^{\mathrm{a}}$ ed., vol. 9, p. 567: "The naming of an area as a provincia did not necessarily result in its immediate annexation. A similarly ambiguous pattern may be seen in the case of the Spanish provinciae. In 218 Hispania was named as the provincia of the consul P. Cornelius Scipio, but, as with the first allocation of Macedonia, there is no suggestion that this was understood to be a claim to sovereignty over the area... For a decade after the successful expulsion of the Carthaginians from the peninsula in 206 by Scipio's son, the later Africanus, the Senate seems to have doubts even about continuing the Roman military presence there. Still less is there any sign of the stablishment of "provincial administration"'.

${ }^{62}$ Roma e le Province, cit. p. 27.

${ }^{63}$ Livio 25, 32, 1-36; Pol. 8, 38; Ap. Ib. 16 ss.; Silio It. Pun. 13, 382; Eutropio 3, 14; vid. al respecto, SALINAS DE FRÍAS, El gobierno de las provincias hispanas, cit. p. 26: "Aunque las fuentes romanas, especialmente Tito Livio, responsabilizan de la derrota a los mercenarios celtibéricos de los romanos, que habrían vendido su neutralidad a los cartagineses favoreciendo de esta manera la derrota de Cn. Escipión y luego la de su hermano, lo cierto es que la decisión de dividir las fuerzas romanas y actuar separadamente contra los 
a los criterios de organización de la misma, situación que se prolonga hasta la reforma de Cayo Graco y Sila, época en la que la administración provincial adquiere un coherencia que se puede considerar como permanente y definitiva.

Después de la derrota de los Escipiones ${ }^{63}$, los comitia $^{64}$ de Roma confieren el imperium proconsulare a Publio Cornelio Escipión, hijo del procónsul Publio Escipión -muerto en el 211- de forma extraordinaria ${ }^{65}$, ya que además de tener sólo 25 años de edad, no había desempeñado previamente, a diferencia de su padre, ninguna de las magistraturas principales y menos aún el consulado. Así, en el año 210 es enviado a Hispania conjuntamente con M. Junio Silano ${ }^{66}$ como propraetor ${ }^{67}$ adiutor ad res gerendas ${ }^{68}$, con 10.000 infantes y mil jinetes,

cartagineses se reveló como un error desastroso que no sólo terminaba con la vida de los dos generales sino que borraba de un solo golpe los progresos de los romanos al sur del Ebro"; sobre el desarrollo de este episodio, CURCHIN, España Romana, cit. p. 41: "Ansiosos de conservar su poder en Hispania y de contener al ejército romano, los cartagineses no sólo suministraban refuerzos a Asdrúbal sino que en 215 le enviaron un nuevo ejército para tener sujeta a Hispania mientras Aníbal conducía sus fuerzas en Italia. Los Escipiones frustraron este movimiento aplastando al ejército de Asdrúbal en una batalla campal junto al Ebro, que tuvo la ventaja adicional de ganarse la lealtad de los hasta entonces desconfiados hispanos", suponemos que por el abandono de los romanos a Sagunto. Lo cierto es que poco después, en el verano de 211, los Escipiones deciden imprudentemente poner fin a la guerra en Hispania y derrotar a los tres ejércitos púnicos. Lo malo del plan es que dependía de la lealtad de los 20.000 hispanos al servicio de Roma, y algunos fueron sobornados (los celtíberos del ejército de Cneo) por lo que el jefe romano se vio superado en número. Así, Publio quedó entre dos frentes, la caballeria númida y el grueso del ejército cartaginés. Roma perdió a los dos generales y todo el territorio del sur del Ebro.

${ }^{64}$ Livio 26, 18, 7-11; Pol. 10, 6, 10; Ap. Iber. 18; vid. al respecto, KNAPP, Aspects of the Roman Experience in Iberia 206-100 B.C., Valladolid, 1977, p. 89-90, en donde supone que la plebe debió convocar los comicios curiados para aprobar una lex curaiata de imperio específica para Escipión, ya que éste no había desempeñado antes ninguna magistratura cum imperio.

${ }^{65}$ RICHARDSON, Hispania y los romanos, cit. p. 34: "Aquel nombramiento, rayano en la inconstitucionalidad, debió de ser fruto del tremendo apoyo político con el que contaba la idea de enviar a otro miembro de la familia de los Escipiones al teatro de operaciones de Hispania. Da la impresión de que el senado se dio cuenta de los riesgos que implicaba aquella decisión, tomada en una de las asambleas del pueblo".

${ }^{66}$ RICHARDSON, ibid: "Entre los miembros del estado mayor de Escipión se incluyó a M. Junio Silano, que al menos había llegado a pretor".

${ }^{67}$ Cfr. JASHEMSKI, The origins and history of the proconsular, cit. p. 25-26, en donde cree que el propretor M. Junio Silano fue enviado también con imperium proconsulare, al mismo nivel que Publio Cornelio Escipión; contra, KNAPP, Aspects of the Roman Experience, cit. p. 91.

${ }^{68}$ Livio 26, 18, 19; la realidad es que los relatos de Livio no resultan nada exactos, opinión casi unánime dentro de la doctrina, pudiendo destacar: SALINAS DE FRÍAS, El gobierno de las provincias hispanas, cit. p. 27: "La cronología de los acontecimientos entre el 211 y el 208 a. c. en Livio, especialmente en lo que respecta a la elección y duración del mandato de los magistrados en Hispania, es sumamente confusa; y el mismo Livio menciona varias veces las contradicciones existentes en sus fuentes. Livio ha retrasado probablemente en un año los acontecimientos, de manera que sitúa la conquista de Cartagena por Escipión en el 210 y no en el 209 a. c. , como hace con mayor exactitud Polibio, por la sencilla razón de que él no puede creer que Escipión estuviese un año en Hispania sin hacer nada. La misma elección de Escipión fue extraordinaria y Livio probablemente tampoco está en lo cierto cuando sitúa la misma en el seno de los comitia centuriata y no de los comitia tributa o concilia plebis, como parece lo más probable"; RICHARDSON, Hispania y los romanos, cit. p. 34, cuando en relación a la utilización de Livio del término propraetor referido a M. Junio Silano, declara en n. 70: "La palabra propraetor es sin duda un anacronismo, pues aparece por primera vez a finales del siglo I a. C., pero la noticia en sí probablemente sea verídica". 
un ejército consular, más 30 naves, sumándole además otros efectivos dentro de los hispánicos ${ }^{69}$. Aprovechando que los ejércitos púnicos estaban operando separadamente, Escipión ${ }^{70}$ los sorprendió marchando en siete días desde el Ebro vigilado por Silano- hasta su principal base en Levante, Cartago Nova ${ }^{71}$, con éxito absoluto ${ }^{72}$ no sólo en el ámbito militar $^{73}$ al disponer ahora de una base firme en el sur de la Península desde donde poder operar- sino incluso en el político, por la habilidad de Escipión al devolver los rehenes indígenas que tenían los cartagineses, atrayendo así a su causa a muchas tribus hispanas ${ }^{74}$. Finalmente, la batalla de Gades $^{75}$ en el año 206 suponen el fin del dominio cartaginés en la

${ }^{69}$ Vid. sobre las tropas, Livio 26, 19, 10-11.

${ }^{70}$ Polibio 10, 6, 1-12, en donde Escipión pronuncia un discurso antes de emprender el ataque de Cartago Nova, con los objetivos de los romanos en la guerra de Hispania; Sobre la parquedad de datos suministrada por Polibio con respecto a la conquista de Hispania, vid. HARRIS, "The Italians and the Empire", en American Academy in Rome, cit. p. 89: "Polybius underestimated two basic facts about the Roman imperialism of his time, one of them being the conquest of Spain, the other being "the Roman organization of Italy"? About the significance of the undoubted shortage of references to Spain in the extant fragments of Polybius it would be possible to argue; after all Polybius thought it worthwhile to visit Spain during the composition of his history, and beyond much doubt his work contributed a good deal, directly or indirectly, to the quite detailed narrative in Appian's Iberike. Perhaps chance or Byzantine copyists are responsible for the shortage of Polybian material on Spain".

${ }^{71}$ Polibio 10, 7, 3-5.

72 Polibio 10, 9, 15; Livio 26, 42-46.

${ }^{73}$ Vid.al respecto, BLÁZQUEZ, España Romana, Madrid, 1996, p. 104. "La caída de la gran ciudad de Cartagena significaba la pérdida para los cartagineses de la mejor base naval de Hispania (Pol. 10, 7), de las vecinas minas de plata y de las explotaciones de esparto, tan necesarias ambas para sustentar el ejército y la escuadra. De hecho Aníbal en Italia, después de la caída de Carthago Nova y de la derrota de su hermano en Metauro, prácticamente se mantiene a la defensiva"; sobre la batalla de Metauro en el 207, en el norte de Italia, en la que resultó vencido Asdrúbal, Livio 28, 42, 14, en un discurso atribuido a Quinto Fabio Máximo, critica la negligencia de Escipión - quien, al margen de una nueva victoria en Baecula en el año 208 a. C, que coloca a los romanos en una posición de claro dominio en la Alta Andalucía, y especialmente los recursos mineros del Saltus Castulonensis- al no dejar bien protegida la ruta de los Pirineos, ya que si la batalla de Metauro hubiese tenido un resultado distinto, el ejército de Anïbal se hubiera reforzado de forma considerable.

${ }^{74}$ Tal acontecimiento viene reflejado en las fuentes literarias: Polibio 10, 34, 35; Livio 27, 17, 1-3; en este sentido, RICHARDSON, Hispania y los romanos, cit. p. 36: "Más significativo aún para los esfuerzos bélicos sería el efecto que este éxito romano tendría sobre los diversos pueblos peninsulares. A su regreso a Tarragona, Escipión se entrevisto con un caudillo español llamado Edescón y poco después vinieron a su encuentro otros dos, Indíbil y Mandonio, de la importante tribu de los ilergetes, oriunda del valle del Ebro", pudiendo resaltar las palabras de Richardson en relación a la proclamación como rey de Escipión hecha por los caudillos hispanos posterior a la batalla de Baecula: "Escipión desestimó graciosamente su aclamación y, con la esperanza de mostrar su carácter regio, solicitó que lo nombraran su general (imperator). Aquel gesto habría de tener una importancia inmensa en el futuro, pues parece ser el origen de la proclamación de los generales victoriosos como imperatores, título que acabaría convirtiéndose en la designación de los emperadores de Roma".

${ }^{75}$ Livio 28, 36-37. 
Península Ibérica y el principio de una administración permanente en la provincia ${ }^{76}$ denominada Hispania. Según SCHULTEN ${ }^{77}$, la división de las dos provincias ${ }^{78}$ existía ya desde el año $206^{79}$, ya que entonces aparecen los dos procónsules por primera vez, aunque no se haga efectiva hasta el año 197. Aquí podemos ver de forma clara las intenciones de los romanos de permanecer en nuestro territorio, ya que después de combatir la amenaza de los cartagineses, bien podía el Senado romano ordenar la retirada de las tropas de Hispania, dejando de denominarla como provincia, pero los actos no sucedieron as ${ }^{80}$. Por primera vez se asignan dos gobernadores para Hispania, L. Cornelio Léntulo y P. Manlio Acidino ${ }^{81}$, y tanto ellos como los que les sucedieron estuvieron con mando prorrogado durante años, con imperium pro consule ${ }^{82}$, a pesar de que, como en el caso de Publio Escipión, casi ninguno era pretor y por tanto ninguno había alcanzado el consulado. Con respecto a la importancia de esta fecha, dice CURCHIN: "The first known Spanish magistrates make their appearance in $206 \mathrm{BC}$, in the context of the Second Punic War. In that year the Roman commander P. Cornelius Scipio captured Castax

${ }^{76}$ Nos parece arriesgado el planteamiento de SALINAS DE FRÍAS, El gobierno de las provincias hispanas, cit. p. 25, cuando declara: "En el reparto de las provincias y las legiones para el 212 Livio menciona que a Publio y Cneo Escipión se les prorrogó el mando sobre las Hispaniae. Es esta la primera vez que se mencionan en plural y que tenemos constancia de la existencia de dos provinciae en la Península Ibérica. Puesto que el mandato del Senado establecía la prórroga, ello significa que ya al menos en 213 existían ambas provincias y que el imperium de Cneo Escipión no era una mera delegación del de su hermano"; contra, RICHARDSON, Hispania y los Romanos, cit. p. 38: "Durante el período que va de 218 a 206, parece que el senado adjudicó la provincia de Hispania, que constituía una sola demarcación, a un único general de rango consular o proconsular, con las únicas excepciones del desastroso mando conjunto de los Escipiones en 212/211 y el envío de C. Nerón como propretor a finales de 211".

${ }_{77}$ Fontes Hispaniae Antiquae 3, Barcelona, 1935, p. 174.

${ }^{78}$ Livio 32, 28, 2.

${ }^{79}$ En esta fecha parece deducirse de diversas fuentes literarias que los indígenas no creían que los romanos fueran a permanecer en la península, una vez expulsados los cartagineses: Livio 28, 24:; 28, 25, 11; 28, 26, 4; 28, 31-34; App. Iber. 37; craso error, porque en el año 206 éstos ya no pensaban abandonar Hispania, conquistada ya Sicilia y Cerdeña.

${ }^{80}$ Publio Escipión regresó a Roma solicitando un triunfo que le fue denegado, con el argumento de que no había desempeñado previamente ninguna magistratura mayor. Con todo, fue elegido cónsul para el año siguiente, el 205; vid. al respecto, RICHARDSON, "The triumph, the praetors and the senate in the early second century BC", en JRS 65, 1975, p. 50-63; sobre el decorrer posterior de Escipión, KEAY, Roman Spain, cit. p. 29: "Scipio returned to Rome, where he was elected to carry the war against Hannibal to Africa. He eventually defeated him at Zama in 202 BC., earning the name of Scipio Africanus".

${ }^{81}$ Vid. con respecto a la posibilidad de que existieran dos provincias antes del año 197 a. C.: RICHARDSON, Hispania y los romanos, cit. p. 47: "El hecho de que existieran dos individuos con imperium pro consule en la península al mismo tiempo quizá indique que desde el principio existieron dos provinciae; pero también podría ser consecuencia de la actitud de los autores de época posterior, que proyectaban a aquella época una situación habitual desde el año 197. Puesto que los generales que sucedieron a Léntulo y Acidino tuvieron, al parecer, provinciae distintas, puede ser que el senado cambiara de idea a este respecto a medida que fue cambiando el carácter de las campañas en las que se vio envuelta Roma”.

${ }^{82}$ Cfr. Plutarco, Emilio Paulo 4, 1; JASHEMSKI, The origins and history of the proconsular, cit. p. 40-47. 
(Castulo) in southeastern Spain and appointed one of its leading citizens, a man of high repute, as a de facto magistrate".

De este modo, asistimos al nacimiento de las provincias hispanas en el año 197 a. C. ${ }^{83}$, como dice Livio ${ }^{84}$ : crescentibus iam provinciis et latius patescente imperio, siendo destinados a las dos provinciae de nueva creación ${ }^{85}$, Citerior y Ulterior $^{86}$, dos pretores ${ }^{87}$, C. Sempronio Tuditano y M. Helvio. Por vez primera dos magistrados ${ }^{88}$ regulares con imperium cumplirían su año de mandato en

83Vid. al respecto, ARNOLD, The Roman System of Provincial Administration, cit. p. 47 : "The next provincial
governments were Hither and Further Spain, which were established in the year 197 B. C. Experience had
taught the Romans the mistake of annual governorships in such a country as Spain, and a special law had
assigned two years of office to the praetors sent to that country"; sobre esta ley, la lex Baebia, vid. Livio,
40, 44: Praetores quattuor post multos annos lege Baebia creati, quae alternis quaternos iubebat creari;
SALINAS DE FRİAS, El gobierno de las provincias hispanas, cit. p. 42: "La lex Baebia de praetoribus,
propuesta probablemente por el cónsul de 181 a. C. M. Baebius Tamphilus. Livio se refiere de pasada a
ella cuando habla de las elecciones de los pretores para el 179, diciendo que en dicho año se eligieron
únicamente cuatro pretores, según lo dispuesto por la lex Baebia, que establecía que debía elegirse cuatro
pretores en años alternos. Si tenemos en cuenta que desde el 188 aproximadamente era normal que los
pretores hispanos prorrogasen por un año su mandato en la provincia, la necesidad de elegir seis pretores
al año, como se venía haciendo desde 197 para abastecer los dos gobiernos provinciales de Hispania, era
una necesidad que sólo se presentaba en años alternos". ${ }^{84} 32,27,6$.

${ }^{85}$ LUZZATTO, Rome e le province, cit. p. 58: "Le due Spagne (Citeriore e Ulteriore) vennero organizzate a province nel 197 a. C. Anche in questo caso, passa oltre un ventennio (dal 218 al 197) fra l'ingresso dei Romani nella penisola e la redactio in formam provinciae. La spiegazione è data dalle necessità della guerra, dapprima contro Cartagine, e successivamente, estromessa quest'ultima nel 206 a. C., ed anche formalmente col trattato del 201, per la sottomissione degli indigeni; sottomissione che si protrarrà attraverso un seguito di guerre spesso gravoso per circa due secoli, fino alla definitiva occupazione dell'intera penisola nel 17 a. C.".

${ }^{86}$ Cfr. RODRÍGUEZ ENNES, Gallaecia: Romanización y ordenación del territorio, Madrid, 2004, p. 29 : "Tras la conquista militar y la sumisión consiguiente, Roma procedía a ordenar jurídicamente el distrito mediante una ley de provincia (lex provinciae)... El texto de nuestra lex provinciae no nos es conocido, pero cabe observar que desde el 197 a. C. los territorios peninsulares no constituían ya una única provincia sino dos -la Citerior y la Ulterior-...".

${ }^{87}$ No existe unanimidad en la doctrina en lo que se refiere a la denominación de los magistrados provinciales hispanos, ya que Livio los llama indistintamente praetores, propraetores, o proconsules. Para MOMMSEN, Römisches Staatrecht II, Leipzig, 1887-89, p. 647, n. 2, era posible que todos los pretores enviados a Hispania tuviesen el imperio proconsular; contra, WILSDORF, en Fasti Hispaniarum Provinciarum, Leipzig, 1878, p. 68 ss. que nombra como praetor proconsule sólo a algunos, entre todos los que las fuentes, como Livio, daban como procónsules; GOTZFRIED, en Annalen der römischen Provinzen beider Spanien von der ersten Besetzung durch die Römer bis zum letzen grossen Freiheitskampf, 218154, Erlangen, 1907, acepta la tesis de Wilsdorf, aunque nos proporciona una lista diferente; la teoría más interesante nos la brinda JASHEMSKI, The origins and history of the proconsular, cit. p. 51-57, en donde afirma que Livio usa la palabra praetor cuando se refiere a la elección de gobernadores provinciales. La palabra propraetor se utiliza cuando su imperium es prorrogado, y cuando Livio se refiere al proconsul, es en virtud de la naturaleza del imperium que ejercen.

${ }^{88}$ Sobre los que sugiere RICHARDSON, "The administration of the Empire”, cit. p. 567: "Although two additional were elected each year from 196 onwards with the needs of Spain in mind, there was no systematic organization even of relationships with the local communities for nearly thirty years". 
la Península ${ }^{89}$, frente a los encargos irregulares y extraordinarios con los que hasta ese momento se había resuelto el problema de los mandos en Hispania ${ }^{90}$. La importancia de este incremento de magistrados ${ }^{91}$ reside en el cambio que se produjo en la estructura de la política romana en general. A partir de la elección de seis pretores al año ${ }^{92}$ fue posible exigir a los candidatos al consulado haber desempeñado previamente la pretura ${ }^{93}$, aunque tal requisito no se plasme hasta la lex Villia annalis de 180.

El motivo de dividir Hispania en dos provincias bien pudiera ser la curiosa configuración del territorio romano en España ${ }^{94}$-la franja costera desde los Pirineos a Cádiz- o la necesidad de contar con un gobernador que tratase con las tribus rebeldes del Norte como los ilergetes y sedetanos- y para mantener segura a Andalucía frente a posibles incursiones púnicas. Incluso factores políticos internos $^{95}$, como el deseo de frenar la influencia de la gens Cornelia en España, eligiendo a partir de ahora a los gobernadores en los comicios por centurias, marco acostumbrado de las magistraturas ordinarias, y por tanto no susceptible

${ }^{89}$ Vid. al respecto, RICHARDSON, Hispaniae, cit. p. 67, en donde establece las diferencias entre el procedimiento empleado en España, y el utilizado en Sicilia, Cerdeña/Córcega: "This is a different procedure from that used at the same time in the other areas in which there was a continuous Roman presence, that is Sicily and Sardinia/Corsica. In both these areas there was a succession of commanders with praetorian imperium from 227, with a consular commander in Sicily when the importance of the war there demanded it. In the 30 years from 227 to 198, these were all men who had been elected praetor or consul, and, when necessary, had their imperium prorogued after their year of office. This was not true of Spain from 210 to 198 ".

${ }^{90}$ Cfr. ROLDÁN HERVÁS, Historia antigua de España I, cit, p. 229.

${ }^{91}$ Seguramente revestidos con un imperium proconsular; vid. al respecto, HERMON, "L'importance de la titulature des gouverneurs provinciaux", cit. p. 80: "Cependant l'imperium des préteurs annuels ne suffit plus pour le gouvernement des deux nouvelles provinces car on leur accorda pour la circostance un imperium proconsulare. On accepte généralement que tous les gouverneurs prétoriens des provinces espagnoles puissent être désignés sous le titre de praetor proconsule...».

${ }_{92}$ RICHARDSON, Hispania y los romanos, cit. p. 52: "Como es habitual en la historia de las instituciones romanas, en cuanto fue instaurado el nuevo marco institucional empezó a ser modificado. El nombramiento de los pretores sugiere que la sucesión en el gobierno de las nuevas provinciae debía producirse anualmente, de acuerdo con el carácter anual de las propias magistraturas. Y así ocurrió de 197 a 193... Hacia 192, sin embargo, la polítiica había cambiado ya, en un principio debido a la presión que suponía la necesidad de generales para la guerra de Oriente contra Antíoco. Al término de este conflicto, hubo en 189 un breve intento de introducir de nuevo el modelo anual, pero, salvo esa única excepción, todos los generales enviados a España desde 192 hasta finales de la década de los setenta permanecerían en su cargo más de un año".

${ }^{93}$ Vid. al respecto, ASTIN, "The lex annalis before Sulla", en Latomus 16, 1957, p. 588-613, y 17, 1958, p. 49-64, en donde defiende la existencia de una disposición que reglamenta la elección a cónsul entre los antiguos pretores desde el año 197, aunque no exista un testimonio directo que avale su tesis.

${ }^{94}$ Cfr. CURCHIN, España Romana, cit. p. 45.

${ }^{95}$ ROLDÁN HERVÁS, Historia Antigua de España I, cit. p. 230: “Así pues, numerosos elementos -factores políticos internos, precavida actitud hacia Cartago e inseguridad en el ámbito provincial- vinieron a coincidir en la definitiva transformación de los territorios peninsulares en dos zonas distintas de intervención militar, encomendadas a sendos pretores". 
de manipulación, como sucedía en la elección hasta el momento realizada ${ }^{96}$ en los comitia tributa, más manejables ${ }^{97}$. Con todo, tal división no prefijaba los límites, aun más, se encargó a los primeros pretores la tarea de fijar el limes de cada provincia, que según fuentes posteriores se estableció al sur de Carthago Nova llegando al Saltus Castulonensis ${ }^{98}$. Al respecto dice KEAY ${ }^{99}$ : "The province of Hispania Citerior comprised the east coast between Carthago Nova and the Pyrenees, and included the inland territory of the Ilergetes and the Ausetani. Tarraco was its principal military base, but there were additional garrisons at towns like Carthago Nova and Castulo. There was probably one at the supplybase at Emporion too".

En este momento histórico, las diferentes comunidades indígenas tenían asimismo diversas formas de organización. Según LUZZATTO ${ }^{100}$, Roma se encontró en territorio hispano con una organización indígena totalmente particular: "A differenza della Sicilia, nella quale Roma viene a contatto con la città-stato di tipo greco, e della Sardegna, nella quale la penetrazione punica sembra aver dato origine, quanto meno lungo le coste, a diverse organizzazioni cittadini, nelle due Spagne la nozione della civitas come ente politicamente organizzato sembra essere stata del tutto eccezionale, e limitata alle colonie greche di fondazione marsigliese (Emporiae Rhosos, forse Sagunto) e a città di fondazione feniciocartaginese quali Gades e Carthago Nova". MANGAS ${ }^{101}$, sin embargo, advierte una similitud mayor entre las ciudades romanas y las que existían en suelo hispano, cuando señala que "se encontraban ya auténticas ciudades, ${ }^{102}$ equivalentes a las civitates romanas, en Ampurias y Rosas, así como en las colonias fundadas por los fenicios y púnicos (se destacan Gades ${ }^{103}$, Cádiz, Malaca, Málaga, Sexi, Almuñécar, Adra, Abdera, Carthago Nova, Cartagena, y Ebusus, Ibiza)", mientras

${ }^{96}$ Vid. al respecto, RICHARDSON, Hispaniae, cit. p. 65: "In 201, as Lentulus and Acidinus had been there for some years, the senate instructed the consuls to refer the matter to the tribunes, so that the plebs might decide which person should hold the imperium in Spain; and again in 199, it was the plebs, on the motion of the tribunes, who ordered that two new commanders should the imperium pro consulibus".

${ }^{97}$ ROLDÁN HERVÁS, Historia antigua de España, cit. p. 230.

${ }_{98}^{98}$ Livio, 32, 28, 11; César, Bell. Civ. 1, 38, 1.

${ }^{99}$ Roman Spain, cit. p. 31.

${ }^{100}$ Roma e le province, cit. p. 62.

${ }^{101}$ Leyes coloniales y municipales de la Hispania romana, Madrid, 2001, p. 12.

${ }^{102}$ Cfr. BURILLO MOZOTA, "Oppida y ciudades estado del Norte de Hispania", cit. p. 35: "En castellano la palabra ciudad es un término ambiguo dado que define indistintamente tanto la urbe, o hábitat construido, como su ordenamiento sociopolítico... En el ámbito romano se distingue el hábitat construido, urbs, de su ordenamiento político, civitas... por lo que una civitas podría tener varios asentamientos urbanos o carecer de ellos".

${ }^{103}$ SHERWIN-WHITE, The Roman Citizenship, cit. p. 185, cuando se refiere a la época de los primeros tratados: "... all these treaties belong to a period before 90 B. C., and many of them can be carried back to a much earlier date; that of Gades, for example, goes back to the year 206 B. C."; 
que era, en cambio, excepcional entre los pueblos del Norte-Noroeste, quienes se organizaban en agrupaciones de aldeas mejor adaptadas a las condiciones del medio natural y de sus formas económicas. Incluso afirma que se puede constatar la realidad de un modelo de ciudad semejante al de la civitas romana en zonas del interior peninsular, sin llegar a generalizarse, lo que vendría a contradecir la antigua tesis de que las ciudades indígenas se localizaban tan sólo en lugares de la costa mediterránea y en el Sur peninsular ${ }^{104}$.

En el año 197 a. C. tiene lugar una gran sublevación ${ }^{105}$ en la Hispania Citerior $^{106}$, probablemente como consecuencia de no respetar los romanos las cláusulas estipuladas en las alianzas firmadas con diversas comunidades indígenas ${ }^{107}$, o, como declara RICHARDSON ${ }^{108}$, por el hecho de que "la población autóctona se había dado cuenta de que los romanos habían decidido quedarse de un modo permanente en la península" ${ }^{109}$. Ante la impotencia de los sucesivos pretores

\footnotetext{
${ }^{104}$ Vid. al respecto, LUZZATTO, Rome e le province, cit. p. 62, en desacuerdo con la tesis de Mangas, explica los dos significados posibles de la palabra civitas para evitar confusiones: "La parola civitas può infatti riferirse tanto ad un complesso edificato a carattere statale di una certa ampiezza, e con certe determinate caratteristiche (quali l'esistenza di edifizi pubblici, di templi, di un foro etc.) quanto ad una comunità organizzata politicamente, che esercita la propria sovranità sopra un determinato territorio, e cioè alla cittàstato del mondo greco-romano. E solo in quest'ultimo senso è appropriato parlare di un'organizzazione cittadina sotto il profilo giuridico", llegando a la conclusión de que se puede "escludere con una certa probabilità la tesi secondo la quale le popolazioni iberiche sarebbero state organizzate a città distribuite piuttosto fittamente, e riconoscere invece come tipico di tali popolazioni l'ordinamento cantonale, in cui la tribù si appoggiava ad oppida, roccheforti per la custodia delle donne, dei fanciulli e dei beni contro aggressioni ostili"; en cuanto a la acepción de oppidum, vid. BURILLO MOZOTA, "Oppida y ciudades estado del Norte de Hispania", cit. p. 36: "Con el término clásico oppidum se define un asentamiento amurallado, sin especificación de su categoría jurídica. Las cifras dadas en el eño 179 por Livio (40, 49) al señalar que Graco recibió la sumisión de 130 oppida, indica que no puede hacer referencias a ciudades", concluyendo en p. 70: "Estos oppida presentan un urbanismo agrupado, con viviendas de planta cuadrangular y espacis internos compartimentados, escasos o nulos edificios monumentales de carácter público: cultural, político o administrativo, con ausencia de espacios abiertos. Lo más alejado, pues, al modelo del ágora griega o del foro romano".

${ }^{105}$ Vid. BURILLO MOZOTA, Ibid. p. 40, en donde dice que a partir del año 206, Hispania se convierte en objetivo de la política expansionista de Roma, declarando: "Las sublevaciones de las poblaciones indígenas es la causa del primer avance de Roma en la Citerior. Catón en el año 195 estabiliza el territorio conquistado hasta el eje que corta perpendicularmente el Ebro, en la actual Zaragoza...”.

${ }^{106}$ Culchas, antiguo aliado de Escipión, que acaudillaba diecisiete ciudades, y Luxinio, este último con las poderosas ciudades de Carmo y Bardo, así como los malacitanos, sexetanos y toda la Baeturia, como recogen las fuentes literarias; vid. al respecto, Livio 33, 19; 33, 21, 6; 33, 25, 8; 33, 26; App. Iber. 39.

${ }^{107} \mathrm{Vid}$. al respecto, BLÁZQUEZ, España romana, cit. p. 114, en donde declara que las fuentes no indican las causas de la sublevación, pero que resulta coherente pensar que viniera motivada por el no cumplimiento de los pactos establecidos : "concretamente con Cádiz, a pesar de haber establecido un foedus en el año 206, en el que se comprometían los romanos a no enviar a ningún pretor, de hecho no lo cumplieron; una causa similar debía motivar la sublevación de las colonias fenicias de Málaga y Sexi, que probablemente se entregarían a los romanos en las mismas condiciones que Cádiz, es decir, se haría un foedus, al igual que probablemente con Culchas y Lixinio".

${ }^{108}$ Hispania y los romanos, cit. p. 53.

${ }^{109}$ De la misma opinión, PINA POLO, "Imperialismo y estrategia militar en la conquista de Hispania Citerior", cit. p. 73: "La inmediata revuelta de la práctica totalidad de pueblos indígenas ibéricos que siguió a la
} 
para sofocar la rebelión ${ }^{110}$, en el año 195 a. $C^{111}$. el Senado envía a un Cónsul, M. Porcio Catón ${ }^{112}$, con los dos pretores que operarían bajo el mayor imperium del cónsul ${ }^{113}$. Sobre la presencia de Catón en Hispania se pronuncia RICHARDSON ${ }^{114}$, para quien: "The period which Cato spent in Spain is of particular importance for an examination of the development of the Spanish provinciae. The main reason for this is the relative fullness of the sources, compared with the brief notices given to events in the peninsula both before and after 195 by Livy, our main source for Spanish affairs in the early second century". Consiguió sofocar la rebelión ${ }^{115}$, pero algunos historiadores ${ }^{116}$ le atribuyen un sentido negativo a su campaña, en la que parece que ejerció una política de devastación y saqueo lejana a cualquier plan de administración ${ }^{117}$, en lo que se refiere a la Hispania Citerior ${ }^{118}$, no consiguiendo

provincialización de Hispania provocaría el envío del cónsul Marco Porcio Catón en el eño 195, y con ello un hito de gran importancia en el proceso de conquista".

${ }^{110}$ Livio 33, 21, 6; 33, 26, 5, en donde se refleja la muerte después de un combate del pretor de la Hispania Citerior, Tuditano.

${ }^{111}$ Livio 34, 8, 1-21,8; Plut. Cat. Mai. 10; Ap. Ib. 39-41; SCHULTEN, Fontes Hispaniae Antiquae 3, 1935, p. 177-194.

${ }^{112}$ Sobre Catón, SCHLAG, Regnum in senatu, Stuttgart, 1968, p. 33-36; ASTIN, Cato the Censor, Oxford, 1978, p. 28-50, 308-310; KNAPP, “Cato in Spain”, en Studies in Latin literature and Roman history II, Bruselas, 1980, p. 21-54.

${ }^{113}$ Vid. al respecto, LUZZATTO, Rome e le province, cit. p. 60: "Si comprende quindi come in tale situazione di guerra quasi constante vengano più volte inviati nella penisola, con competenza indiscriminata nelle due province, eserciti consolari (così, p. es., nel 195 con Marco Porcio Catone, nel 153/152 con M. Fulvio Nobiliore e M. Claudio Marcella, nel 134 con P. Cornelio Scipione Emiliano); e come pure, in taluni periodi contrassegnati da particolari preoccupazioni di politica estera (come nel 171/168, in occasione della terza guerra macedonica) le due province venissero riunite in una sola".

${ }^{114}$ Hispaniae, cit. p. 80.

${ }^{115}$ Livio, 34, 9, 16.

${ }^{116}$ Otros, sin embargo, no dudan a la hora de destacar sus logros, como PINA POLO, "Imperialismo y estrategia militar en la conquista de Hispania Citerior", cit. p. 73, en donde declara que la llegada de Marco Porcio Catón en el año 195 supone: "un hito de gran importancia en el proceso de conquista", continuando después con la valoración : "De ahí la relevancia de la incursión de Catón, a quien se deberían las primeras noticias seguras de carácter geográfico sobre el interior de Hispania que llegaron a Roma".

${ }^{117}$ Vid. al respecto, ROLDÁN HERVÁS, Historia Antigua de España I, cit. p. 234, en donde ironiza sobre la supuesta ' pacificación' de Catón, declarando que más que un hito en la historia de la conquista romana de Hispania, "el cónsul sólo representa a lo sumo el paradigma de la pobre y brutal política que, tras la Segunda Guerra Púnica, aplicó el estado romano en el ámbito provincial"; dice además que Catón se limitó a disposiciones sobre la marcha, sin ninguna planificación, y trae a colación los impuestos sobre las salinas y minas, cuando afirma: "Entre las supuestas disposiciones administrativas y financieras se cuenta el establecimiento de tributos sobre las minas de hierro y plata. Aunque limitado al norte del Ebro, se trata de la primera evidencia directa del interés del estado romano en la explotación de los recursos de mineral peninsulares, que en fechas posteriores se extenderá a otras zonas. Más que una sistematización de los ingresos fiscales, hay quue pensar de nuevo en medidas ad hoc y en una recaudación directa, extraída de los particulares que explotaban estas minas".

${ }^{118}$ Seguimos a SALINAS DE FRÍAS, El gobierno de las provincias hispanas, cit. p. 58, cuando declara: "Para algunos historiadores, la actividad organizadora de Catón es muy importante para el desarrollo y organización de las provincias hispanas; pero a nuestro juicio la importancia que se ha concedido a Catón en ese sentido es excesiva... Lo que caracteriza al gobierno de Catón en Hispania es más bien su avidez de botín y riquezas y el énfasis puesto, por esta vía, en el ahorro de fondos estatales". 
además la pacificación definitiva ${ }^{119}$ de la provincia asignada, al margen de no respetar los límites de la misma ${ }^{120}$. A la vista de lo expuesto, no parece que ayudara mucho a los planes de la administración provincial, aunque se le atribuya el establecimiento de impuestos en salinas y minas de plata y hierro de la Hispania Citerior $^{121}$, así como la regulación del pago del stipendium ${ }^{122}$, elemento básico de la administración provincial ${ }^{123}$. Prueba de lo anterior son las guerras continuas ${ }^{124}$ contra los lusitanos, los vacceos y los celtíberos, tras el regreso de Catón a Roma, quien además se había llevado parte de las tropas para celebrar su triunfo ${ }^{125}$.

${ }^{119}$ De forma distinta piensa PINA POLO, "Imperialismo y estrategia militar en la conquista de Hispania Citerior", cit. p. 74, cuando afirma: "Catón logró mediante la fuerza y la represión brutal la pacificación definitiva de los pueblos del ámbito cultural ibérico, al tiempo que señaló el camino a la expansión hacia el interior de Hispania, donde desde entonces el Estado romano se encontró como principales adversarios a los lusitanos en la Ulterior y a los celtíberos en la Citerior".

${ }^{120}$ Cfr. RICHARDSON, Hispania y los romanos, cit. p. 54: “Catón no sólo no sometió la región que le había sido asignada, sino que además actuó fuera de ella".

${ }^{121}$ Livio 34, 21, 7: pacata provincia vectigalia magna instituit ex ferrariis argentariisque, quibus tum institutis locupletior in dies provincia fuit; sobre la veracidad o no del traspaso al Estado romano de las minas, y su explotación posterior por medio de las societates publicanorum, vid. a favor: BADIAN, Publicans and sinners, Oxford, 1972, p. 32 ss; contra, RICHARDSON, "The spanish mines and the development of provincial taxation in the second century BC", en JRS 66, 1976, 139-152.

${ }^{122}$ Se ha discutido mucho si en 197, o en época de Catón, se había regularizado el pago del stipendium; a favor se ha argumentado que Livio menciona a partir del año 195 el argentum oscense como elemento del botín de los generales romanos a su regreso de Hispania; identificado ese argentum con los denominados "denarios ibéricos", dichas monedas habrían sido acuñadas por comunidades indígenas para pagar el stipendium a Roma, lo que demostraría la existencia de un sistema regular de tributación desde la misma fecha de establecimiento de las provincias o poco después; contra, tanto en la cronología propuesta como en la finalidad de dichas monedas, RICHARDSON, Hispaniae, cit. p. 92: “ The coins themselves, from indications of usage, can only give a very approximate indication of their date, and the only reason for placing their introduction at the very beginning of the second century is the mention of 'argentum oscense' by Livy. Yet, if they were introduced to pay Roman taxes in 197, the notices in Livy are very odd, for there they appear among the booty of proconsuls who governed Spanish provinces in 197, 196 and 195", lo que implicaría que las monedas tendrían que haber sido inmediatamente capturadas en grandes cantidades a las tribus rebeldes. Concluye el autor con su propia teoría, según la cual :"The argentum oscense of Livy is probably some other local coinage, such as the Iberian coins struck in imitation of the drachmas from Emporion, and their appearance in the I90s is no evidence for the existence of a complex system of taxation at this date".

${ }^{123}$ Vid. al respecto, LUZZATTO, Roma e le province, cit. p. 15: "Tuttavia la più caratteristica contrapposizione fra l'Italia e le province era costituita fin dall'epoca di Augusto dall'immunità tributaria del suolo italico, mentre lo stipendium e il tributum... gravano sul suolo provinciale".

${ }^{124}$ ROLDÁN HERVÁS, Historia antigua de España, cit. p. 235, en donde dice que los pretores del año 194 a. C. comprobaron, de forma especial Sexto Digitio en la Citerior :"La precariedad de las medidas catonianas al tener que enfrentarse contra una formidable coalición de las tribus del Ebro, donde perdió la mitad de su ejército".

${ }^{125}$ Sobre el regreso de Catón al frente de sus tropas - cuya presencia en Roma era imprescindible para obtener el triunfo- vid. Livio 34, 43, 3 y 8; PINA POLO, "Imperialismo y estrategia militar en la conquista de Hispania Citerior", cit. p. 74: “A su vuelta a la Urbe, el cónsul Catón celebró por sus victorias en Hispania un gran triunfo, al que acompañó con el ingreso en las arcas del Estado de un enorme botín". 
En el año 180, se asigna la Hispania Citerior a Tiberio Sempronio Graco ${ }^{126}$, quien, prorrogado su mandato para el 179 , penetra in ultima Celtiberia ${ }^{127}$. Su habilidad para hacer tratados con los celtíberos ${ }^{128}$ demostró que no solo se podía conquistar con la fuerza. Así, sin romper las tradicionales alianzas con las oligarquías locales ${ }^{129}$, Tiberio Graco inició una política de creación de ciudades para asentar a poblaciones indígenas ${ }^{130}$, pareciendo que comprendía los motivos de las frecuentes revueltas de la población indígena de Hispania: la marginalidad de amplios sectores de la población que no disponían de medio alguno de subsistencia $^{131}$. De este modo, fundó una ciudad llamada Gracurris ${ }^{132}$, en el alto valle del Ebro ${ }^{133}$ y también Iliturgi ${ }^{134}$, en donde existe una inscripción dedicada a Graco por el populus Iliturgitanus ${ }^{135}$. Sin restar mérito a su esfuerzo en cuanto al mantenimiento de las estructuras provinciales romanas, no podemos afirmar que su labor constituyese el fundamento de la organización provincial ${ }^{136}$, sino una

${ }^{126}$ Siendo su colega de la Hispania Ulterior L. Postumio Albino; sobre ambos, se pronuncia RICHARDSON, Hispania y los romanos, cit. p. 58: “ Graco y su colega, L. Postumio Albino, el pretor destinado a la Hispania Ulterior, gobernaron las dos provincias desde finales de 180 hasta que llegaron sus sucesores en 178. Debido a la laguna existente al comienzo del libro LXI de la Historia de T. Livio, sabemos muy poco de lo que hicieron durante su mandato, pero da la impresión de que siguieron el ejemplo de algunos de sus antecesores al convenir coordinar sus campañas a comienzos de 179. A juzgar por los resultados, fueron más eficaces de lo habitual".

${ }^{127}$ Livio 40, 47, 1.

${ }^{128}$ Vid. sobre los tratados de Graco con los celtíberos, Livio, 40, 47, 3-10; 40, 49, 4-7; SALINAS, Conquista y romanización de Celtiberia, Salamanca, 1986, p. 12-14.

${ }^{129}$ Apiano, Ib. 43, al relatar las negociaciones entre Segeda y Roma al inicio de la guerra numantina, describe lo fundamental de los acuerdos de Graco con los celtíberos: Pago de un tributo a los romanos, contribuir con tropas auxiliares al ejército romano, y prohibición de fortificar nuevas ciudades.

${ }^{130}$ Vid. al respecto, NICOLET, Le métier de citoyen dans la Rome républicaine, 1976, p. 47: "Enfin, vers la fin du IIe siècle, avec Caius Gracchus, commença une nouvelle phase dans l'histoire de la colonisation romaine: les déductions coloniales furent essentiellement considérées, dès lors, comme un moyen de donner des terres à des citoyens qui n'en avaient plus, ou de mettre en valeur des territoires. Dans tous les cas, cependant, le procédé restait un moyen de romanisation et d'integration très efficace".

${ }^{131}$ Cfr. MANGAS, Historia universal, cit. p. 130, en donde afirma: "Y así, con Sempronio Graco, se manifestó la cara buena del imperialismo romano".

${ }^{132}$ Que se corresponde con Alfaro, La Rioja.

${ }^{133}$ Livio, ep.41; Festo, 86 (L).

${ }^{134}$ Mengíbar, Jaén.

${ }^{135}$ Vid. sobre los problemas del epígrafe: Ti. Sempronio Graccho/deductori/populus Iliturgitanus, CASTILLO, "De epigrafía republicana hispano romana", en Reunión sobre epigrafía hispánica de época romanorepublicana, Zaragoza, 1986, p. 146-150.

${ }^{136}$ RICHARDSON, Hispania y los romanos, cit. p. 68, apoya la tesis de considerar la actividad organizadora de Graco como de carácter general; Vid. BADIAN, Foreign clientelae, p. 1 22-123, en donde relata que los tratados suscritos por Graco con los celtíberos adolecían de la falta de ratificación por parte de los comicios, siendo solamente ratificados por el Senado; LUZZATTO, Roma e le province, cit. p. 39-40: "L'organizzazione della provincia è compiuta, di regola, dal condottierro che ha conquistato ed anesso il territorio, ma che è tenuto a seguire, al riguardo, le direttive del senato. Tale direttive potevano tuttavia essere impartite in due modi: o il governatore procedeva direttamente all'organizzazione del territorio 
ayuda en la pacificación de la provincia, y el principio de una reordenación del territorio más acorde con la realidad de Hispania.

En efecto, podemos comprobar el interés del Senado en regular cada vez más la administración de Hispania, primero en la respuesta a la reclamación de los hispanos en el año $171^{137}$ ante los abusos y arbitrariedades de algunos pretores cometidos durante su mandato ${ }^{138}$, cuando el Senado decidió que a partir de entonces ningún magistrado estableciese el precio del grano en Hispania, ni se impusiesen prefectos en las ciudades para recaudar los tributos ${ }^{139}$, y segundo, en la fundación ${ }^{140}$ de Carteia $^{141}$ como colonia libertinorum ${ }^{142}$ ese mismo año, siendo la primera colonia ${ }^{143}$ latina situada fuera de Italia ${ }^{144}$.

provinziale, salva la successiva ratifica del senato; oppure questo ultimo inviava una commissione, per lo più di dieci legati, muniti di potere consultivo ma privi di imperium... L'organizzazione definitiva del territorio avveniva mediante la lex provinciae: una lex data nella quale il magistrato, in forza della delega precedentemente ottenuta dai comizi, delineava lo statuto e le caratteristiche fondamentali dell'amministrazione della provincia".

${ }^{137}$ MANGAS, Historia universal, cit. p. 130: "En el año 171, una comisión de hispanos llegó a Roma para protestar por los expolios y vejaciones a que eran sometidos a veces por los gobernadores; el Senado les recomendó que eligieran a sus patronos para que los protegieran y defendieran sus quejas ante el Senado", escogiendo los de la Citerior a M. Porcio Catón y a P. Cornelio Escipión, y los de la Ulterior a L. Emilio Paulo y a Galo Sulpicio, lo que pone de relieve que aunque algunos habían sido muy duros con los hispanos, fueron elegidos sabiamente porque eran los hombres más influyentes del senado romano.

${ }^{138}$ Vid. al respecto, SALINAS DE FRÍAS, El gobierno de las provincias hispanas, cit. p. 164: "La libertad de acción de los gobernadores, la imposición de tributos extraordinarios, de indemnizaciones de guerra a los enemigos, y el deseo sincero o forzado de los provinciales de agasajjar y mostrar su adhesión a los gobernadores, permitieron a éstos amasar fortunas mediante procedimientos que sólo distaban de la corrupción y la venalidad lo que el talante personal de cada individuo. De esta manera, la casi constante reclamación de los provinciales es la que se hace contra los abusos de los magistrados proovinciales y la excesiva fiscalidad romana".

${ }^{139}$ Livio 43, 2, 1-12.

${ }^{140}$ Vid. al respecto, RICHARDSON, Hispaniae, cit. p. 119: "Carteia, near Algeciras, resulted from a direct appeal to the senate. In 171 an embassy arrived in Rome, representing over 4.000 men, the offspring of Roman soldiers and Spanish women who had no right of conubium, who asked for a town in which to live. The senate decreed that they should give their names to L. Canuleius, the praetor to whom the Spanish provinces had been alloted, and also the names of those whom they had manumitted and that a colony was to be founded at Carteia, into which the native inhabitants of Carteia could be enrolled. This was to be a Latin colony, and to be called 'libertinorum', 'of the freedmen'"; añade el mismo autor en una obra posterior, Hispania y los romanos, cit. p. 74: "Como tal, la nueva fundación debía de ser una colonia latina, esto es, una fundación romana sin derechos de ciudadanía, aunque provista de otros derechos previstos en el sistema jurídico romano, entre ellos el conubium -derecho al matrimonio mixto- y el commercium o derecho a la compra-venta de ciertos artículos en pie de igualdad con los ciudadanos romanos".

${ }^{141}$ GARCÍA Y BELLIDO, "Las colonias romanas de Hispania", en AHDE 29, 1959, p. 450: "Esta colonia gozaría del derecho latino y se llamaría de libertos, Colonia civium latinorum et libertinorum. El hecho ocurrión en el año 171. Las inscripciones son pocas y no aportan datos sobre su carácter colonial, salvo una lápida probablemente ya cristiana, hallada en San Roque en 1928 por la que conocemos a un Aurelius Felix Ingenuus civis Romanus carteiensis".

${ }^{142}$ GARCÍA Y BELLIDO, "Las colonias romanas de Hispania", en AHDE 29, 1959, p. 450: "Esta colonia gozaría del derecho latino y se llamaría de libertos, Colonia civium latinorum et libertinorum. El hecho ocurrión en el año 171. Las inscripciones son pocas y no aportan datos sobre su carácter colonial, salvo una lápida probablemente ya cristiana, hallada en San Roque en 1928 por la que conocemos a un Aurelius Felix Ingenuus civis Romanus carteiensis". 
A mediados del siglo II a. C., se produce un escenario convulso, lleno de guerras y revueltas, que en nada ayudan a consolidar la realidad de Hispania. En primer lugar, por la revuelta de los lusitanos y vetones en el 155-154, en la Hispania Ulterior $^{145}$, primero vencedores frente a los ejércitos romanos, pero finalmente derrotados por L. Mumio ${ }^{146}$, pretor de la Ulterior en el 153, constituyendo los años siguientes episodios continuos de enfrentamientos entre romanos y lusitanos ${ }^{147}$. En segundo lugar, por la revuelta originada en la Citerior, en el año 154, como consecuencia de una disputa entre el Senado romano y la ciudad celtibérica ${ }^{148}$ de Segeda ${ }^{149}$, que formó una confederación con ciudades vecinas, negándose a suministrar tropas y pagar tributo alguno ${ }^{150}$. Este hecho supuso el inicio de

${ }^{143}$ Resulta interesante la aportación de MANSUELLI, Roma e le province, II. Topografía, urbanizzazione, cultura, Bolonia, 1985, p. 83: "La prima formazione romana, l'Italica di Scipione nella Betica, non ebbe rango di colonia, né si dette luogo, per lungo tempo, a deduzioni, tanto che soltanto nel 171 si costituì, sempre nella Betica, la prima colonia, di diritto latino, Carteia, ma con elementi del meticciato romanoiberico e con altri di origine libertina (Colonia Libertinorum). Colonie forse latine furono più tardi nel 123 Palma e Pollentia nell' isola di Maiorca, dove Q. Cecilio Metello Balearico dedusse contingenti di Italici scelti fra quelli già affluiti in Spagna al di fuori di ogni programma regolare. Sono incerti l'antichità e lo stesso ordinamento coloniale di Valentia che sarebbe stato l'unico centro urbano di carattere romano nella Tarraconese".

${ }^{144}$ Vid. al respecto, MANGAS, Leyes coloniales y municipales de la Hispania romana, cit. p. 13, en donde declara que el grupo de ciudades privilegiadas que conforman colonias y municipios era muy reducido en la etapa republicana anterior a César, y aunque Carteia -situada en la bahía de Algeciras, San Roque, Cádiz- fue la primera colonia latina fuera de Italia, "el proceso de integración de ciudades hispanas en el grupo de las privilegiadas siguió siendo muy lento, pues Corduba (Córdoba) no pasó a ser colonia latina hasta el 153 a. C., Palma (Palma de Mallorca) y Pollentia (Pollensa, isla de Mallorca) hasta el 123 a. C., e Ilerda (Lérida) hasta el 89 a. C.”.

${ }^{145}$ App. Iber. 56-57; vid.sobre el testimonio de Apiano, SALINAS DE FRÍAS, El gobierno de las provincias hispanas, cit. p. 68-69: "Aunque se ha discutido mucho el valor historiográfico de la Iberiké y las fuentes utilizadas por Apiano para su composición, su obra por lo menos proporciona un relato coherente y libre de los excesos de la analística utilizada por Livio".

${ }^{146}$ Vid. al respecto, CURCHIN, España romana, cit. p. 51: "L. Mumio (famoso posteriormente por el saqueo de Corinto en 146), que, después de una costosa derrota inicial -9.000 muertos, si podemos dar crédito a Apiano-, reagrupó sus fuerzas y se apuntó una gran victoria sobre los lusitanos".

${ }^{147}$ En el año 152, M. Atilio después de tomar una de las ciudades de los lusitanos, firmó tratados con estos y los vettones en los que contemplaba un reparto de tierras, como destaca SALINAS DE FRÍAS, La organización tribal de los vettones, Salamanca, 1982, p. 34; posteriormente, se suceden los engaños para vencer a los lusitanos, prometiéndoles Galba en el año 149 tierras a cambio de las armas, pasándolos sin embargo a cuchillo cuando fueron desarmados, según relato de App. Iber. 58-60.

${ }^{148}$ Vid. al respecto, MANGAS, Historia universal, cit. p. 131: "El pretexto aducido por Roma para justificar el inicio de las operaciones militares contra los celtíberos fue la acusación de que éstos no cumplían los pactos que habían firmado con Sempronio Graco. De nada les sirvió a los celtíberos aducir razones para demostrar que no eran ciertas tales acusaciones", dando como argumento la política de expansión territorial romana para entender las guerras de este momento histórico.

${ }^{149}$ Sobre esta ciudad, resulta de interés la obra colectiva anteriormente señalada, Segeda y su contexto histórico, cit. passim, ya que contiene información detallada sobre este importante núcleo de población; en concreto, vid. el artículo de BURILLO MOZOTA, "La ciudad estado de Segeda", p. 203 ss. en donde recoge un elenco de fuentes de todo tipo acerca de esta ciudad; en p. 204 declara: "Los acontecimeintos desencadenantes de la guerra celtibérica del 153 al 133, proporcionan una información precisa sobre la existencia de una ciudad denominada Segeda... Es calificada por Diodoro $(31,39)$ como pequeña ciudad de la Celtiberia y por Apiano (Iber. 44-47) como ciudad de los celtíberos belos, grande y poderosa, y a 
las guerras celtibéricas ${ }^{151}$ ya que la respuesta del Senado ${ }^{152}$ no se hizo esperar, designando un cónsul como gobernador de la Citerior para 153, Q. Fulvio Nobilior, y decretando que desde entonces, los cónsules ${ }^{153}$ ocupasen su cargo el uno de enero en lugar del uno de marzo- por causa de la insurección de los hispanos ${ }^{154}$. Nobilior impidió que los segedenses concluyeran el amurallamiento de la ciudad, pero no tuvo éxito ${ }^{155}$ frente a Numancia ${ }^{156}$, hasta que a comienzos del año 151 las tribus se entregan ${ }^{157}$ al cónsul Marcelo ${ }^{158}$, sustituido en el mismo año por L. Licinio Lúculo ${ }^{159}$ para la Citerior y Servio Sulpicio Galba ${ }^{160}$ para la Ulterior ${ }^{161}$,

su aliada Numancia como la más poderosa ciudad de los arevacos. Roma declara expresamente la guerra a Segeda al acusarle de incumplir los pactos de Graco por obligar a otras ciudades más pequeñas a establecerse junto a ella y construir una nueva muralla, movilizando un ejército de casi 30.000 hombres a cargo del cónsul Nobilior. También nos informa de la alianza de Segeda con los arévacos, formando una coalición con Numancia capaz de levantar 25.000 hombres. El primer enfrentamiento entre estos dos grandes ejércitos supone una momentánea derrota romana, pero de tal calibre que ese día, 23 de Agosto día de Vulcano, se considera nefasto para Roma".

${ }^{150}$ Cfr. CURCHIN, España romana, cit. p. 51.

${ }^{151}$ Polibio, 3, 4, 12.

${ }^{152}$ Cfr. CURCHIN, España romana, cit. p. 51, para quien la posición del Senado en este asunto "parece exagerada".

${ }^{153}$ Vid. al respecto, SALINAS DE FRÍAS, El gobierno de las provincias hispanas, cit. p. 163: "Durante las guerras del 153-133 a. C. la Hispania Citerior, y, ocasionalmente la Hispania Ulterior fueron provincias consulares. Nuevamente la necesidad de enviar ejércitos mayores, pero también los deseos de los miembros de la aristocracia por conseguir la gloria más alta, que era la que daba el triumphus, mediante una guerra adecuada a ello, hizo que se enviase a los magistrados investidos del imperium más alto".

${ }^{154}$ Livio, Per. 47, aunque también pudo influir el que el calendario estaba atrasado con respecto a las estaciones; vid. al respecto, BRIND’AMOUR, Le calendrier romain, Ottawa, 1983, p. 130-132; RICHARDSON, Hispaniae, cit. p. 134-136, en donde motiva la decisión de enviar un cónsul en la escasez en ese momento- de provincias necesitadas de mando militar, como declara en p. 135: "If it was both the right and duty of a consul to command Roman troops, it was necesssary for the senate to assign military areas as consular provinces".

${ }^{155}$ Vid. al respecto, CURCHIN, España romana, cit. p. 52: "El intento de Nobílior de tomar Numancia al asalto fracasó cuando sus elefantes asustados pisotearon a los propios romanos".

${ }^{156}$ App. Iber. 44-47; muy interesante, SCHULTEN, Historia de Numancia, Barcelona, 1945, passim.

${ }^{157}$ Vid. sobre el tratado de Marcelo con los celtíberos y el significado de deditio en RICHARDSON, Hispaniae, cit. p. 141-147, especialmente p. 143: "The senate clearly did not reject Marcellus' proposal without discussion, but the effect of their decision was to make it impossible for anything less than a deditio to be accepted in the future"; la clemencia mostrada por Marcelo no fue bien vista por el Senado aun cuando sus críticas no fueron directas contra él, como dice el autor en p. 144: "The absence of any mention of subsequent attacks on Marcellus in the senate indicates that both his acceptance of the deditio and his declaration that the Celtiberians were free were in fact not rejected by the senate, despite the flouting of their intentions. It may well be that the large quantity of silver which he brought back helped to quieten his critics".

${ }^{158}$ Polibio 35, 2-3; App. Iber. 49-50;

${ }^{159}$ Polibio, 35, 2, 9; App. Iber. 51, 215, en donde se muestra un personaje ávido de fama y necesitado de dinero, que esperaba conseguir en sus incursiones en la Hispania Citerior.

${ }^{160}$ Vid. al respecto, la traición de Galba a los lusitanos, en App. Iber. 56-60; Livio, Per. 49; Suetonio, Galba, 3; Valerio Máximo, 9, 6, 2; Orosio, 4, 21, 10; SIMON, Roms Kriege in Spanien 154-133 v. Chr., Francfurt, 1962, p. 60-67.

${ }^{161}$ Aunque Galba, a su regreso a Roma fue procesado por un mal comportamiento -por otro lado, resultando absuelto- por lo que estimamos interesante la declaración de RICHARDSON, "The administration of the Empire", p. 577: "Normally, though the gobernor might slaughter and anslave the inhabitants of his provincia, as Ser. Sulpicius Galba did the Lusitanians in $150 \ldots$ no action would be taken against him during his tenure", que explica que en raras ocasiones se desposee a un gobernador de su imperium durante su mandato. 
considerando el Senado que eran más adecuados para el cargo que el anterior ${ }^{162}$, por su reconocida dureza para negociar. De hecho, la rebelión de Viriato fue consecuencia directa de los abusos de Galba, cuando los lusitanos que lograron escapar a la matanza ${ }^{163}$ perpetrada por éste -con engaño- se unen y comienza un período $^{164}$ de continuas victorias para el caudillo lusitano, hasta su asesinato en el 139 por traición ${ }^{165}$ y no por tácticas de guerra.

La situación reinante en Hispania en el 139 era francamente complicada, porque a la realidad de los innumerables enfrentamientos con los lusitanos en la Ulterior, hay que sumarle la prolongada guerra de Numancia ${ }^{166}$, que continuaba desconcertando al gobierno de Roma ${ }^{167}$. Después de la derrota del cónsul Mancino $^{168}$ en el 137, Roma percibe que la situación en la Hispania Citerior es cada vez más difícil, y que la imposibilidad de pacificar todo su territorio en orden a la promulgación de una lex provinciae, hace necesaria una intervención ejemplar. Sin embargo, los primeros pasos, de la mano de M. Emilio Lépido a finales del 137, fueron el peor ejemplo ${ }^{169}$ a seguir en aras de una conquista definitiva, llegando el Senado por vez primera- a privar a Lépido de su poder proconsular. Una decisión sin duda realmente inusual, como declara RICHARDSON ${ }^{170}$ : "Theoretically a governor could have his imperium removed, but in practice so severe a measure was used only in exceptional circumstances". Así, nos refiere que en el año 136 a. C. M. Emilio Lépido "The proconsul in Hispania Citerior, not only attacked the tribe of the Vaccaei in direct contravention of an order brought to him by a messenger from the Senate, but subsequently suffered a disastrous defeat, and as a result was deprived of his imperium".

${ }_{162}$ Cfr. CURCHIN, España romana, cit. p. 52.

${ }^{163}$ App. Iber. 50, 211; 55, 232; vid. al respecto, RICHARDSON, Hispania y los romanos, cit. p. 63, en donde dice que con la unión de fuerzas de Lúculo y Galba en el 150, se llevó a cabo "la espantosa matanza de los lusitanos".

${ }^{164}$ Invadiendo en primer lugar Turditania; sobre cronología, ASTIN, "The Roman commander in Hispania Ulterior in 142 a. C.", en Historia 13, 1964, p. 245-254.

${ }^{165}$ Lo asesinaron lusitanos traidores, sobornados por Cepión, cónsul en el 140 en la Hispania Ulterior, testimonio que nos brinda App. Iber. 70, 74; Diodoro Sïculo, 33, 21; Floro 1, 33, 17.

${ }^{166}$ Vid. al respecto, SCHULTEN, Geschichte von Numantia, Munich, 1933, p. 41-48.

${ }^{167}$ Livio, Per. 56, en donde declara que la guerra de Numancia se había hecho interminable debido a la incompetencia de los generales, para vergüenza del pueblo romano.

${ }^{168}$ Fue vencido y obligado a rendirse, como recoge App. Iber. 80, 346-347; vid. sobre los términos del acuerdo, BROUGHTON, The magistrates off the Roman Republic, vol. 1, Cleveland, 1950, p. 484; SIMON, Roms Kriege in Spanien, cit. p. 149-159.

${ }^{169}$ CURCHIN, España Romana, cit. p. 56, en un comentario duro con respecto a Lépido, cuando afirma que:“Atacó estúpidamente a los vacceos (afirmando falsamente que estaban ayudando a Numancia) y después de un largo sitio sin éxito a Palantia fue retirado por el Senado por haber envuelto a Roma en una nueva guerra cuando la que se estaba librando presionaba duramente".

170 "The administration of the Empire", cit. p. 577. 
Se ofreció el mando a Cornelio Escipión Emiliano ${ }^{171}$, que había destruido Cartago en el año 146, que fue el vencedor final contra Numantia ${ }^{172}$, a la que doblegó rodeando la ciudad, y aislándola con una circumvallatio de todo contacto externo ${ }^{173}$, hasta llegar a la rendición incondicional ${ }^{174} \mathrm{en}$ el año 133 , arrasándola a continuación ${ }^{175}$.

A tenor de lo expuesto, podemos observar como durante toda la República la actividad militar era considerada la actividad principal de los magistrados provinciales expresada mediante el imperium que se les confería-, pero será a partir del 133 a. C. cuando las funciones de carácter administrativo alcancen una importancia mayor. La guerra numantina acabó con el envío de una comisión senatorial de diez legados ${ }^{176}$ cuya tarea consistiría en implantar un orden pacífico en los lugares ya conquistados ${ }^{177}$, organizando las zonas ya ocupadas por los romanos ${ }^{178}$, en lo que se conoce como el comienzo de las estructuras provinciales del imperio ya desarrollado ${ }^{179}$, aunque no se sabe mucho más. Como dice CURCHIN 180 : "No se sabe nada más de los comisionados, aunque podemos especular que regularon los términos de la paz (incluyendo una indemnización

${ }^{171}$ Cfr. BROUGHTON, The magistrates of roman republic, cit. p. 490 y 491, n. 1, sobre la elección de Escipión.

172 App. Iber. 95, 412; 96, 418, en donde se dice que un gran número de numantinos prefirieron suicidarse antes que rendirse.

173 Vid. al respecto, SCHULTEN, Historia de Numancia, cit. p. 101:"No era el bloqueo el único medio para vencer a Numancia. Es verdad que por el oeste, por el sur, y por el sudoeste, lo mismo los ríos que la escarpada pendiente de la colina dificultaban el ataque, pero toda la parte oriental se prestaba fácilmente al asalto a causa de la moderada pendiente de la colina y de la carencia de ríos... La posibilidad de un asalto era manifiesta. Sin embargo, Escipión no la tomó en consideración. No podía intentar con sus malos soldados lo que mejores tropas no habían logrado. Por eso le vemos desde un principio entrenar a su ejército para el bloqueo".

${ }^{174}$ SCHULTEN, Ibid. p. 150: "El hambre apretaba de modo terrible. En situación tan calamitosa enviaron los numantinos cinco emisarios a Escipión, con el fin de alcanzar de él una capitulación honrosa...Pero Escipión permaneció inconmovible; sabía por los prisioneros cuál era la situación de la ciudad y exigía su entrega con las armas. Cuando regresaron los enviados con tal respuesta, la ibérica fiereza se encedió hasta el paroxismo", sin ceder a las pretensiones, por lo que tuvieron que llegar al canibalismo, y: "Sólo cuando este horrendo suministro se agotó, se decidió la entrega".

${ }^{175}$ Según App. Iber. 96-98, este acto fue criticado por algunos senadores por haber destruido la famosa fortaleza sin autorización del Senado.

176 App. Iber. 99, 428.

${ }^{177}$ Por Escipión y previamente sometidos por Bruto; sobre este último, RODRÍGUEZ ENNES, Gallaecia, cit., p. 22 ss.

178 Vid. al respecto, SUTHERLAND, The Romans in Spain, Londres, 1939, p. 88-91.

${ }^{179}$ Cfr. RICHARDSON, Hispania y los romanos, cit. p. 68, en donde atribuye a Tiberio Sempronio Graco el mérito de ser el pionero en las acciones que conducirían al establecimiento de esas estructuras provinciales, añadiendo además en p. 69: "El gobierno de Graco en Hispania Citerior se halla además relacionado con la introducción de un sistema fiscal más organizado debido al cambio que se produjo a raíz de su llegada a esta provincia en 180 en la utilización del término stipendium para designar al tributo recaudado en España".

${ }^{180}$ España romana, cit. p. 59. 
de guerra y la creación de un ager publicus en las zonas conquistadas). Se puede dudar de que los límites interprovinciales se extendieran a la nueva frontera".

Durante el siglo II y comienzos del I a. C. se fueron creando núcleos de población itálica con o sin estatuto jurídico reconocido ${ }^{181}$, al lado de un número desconocido de población itálico-romana que, seguramente por motivos comerciales, se habían asentado en la Península ${ }^{182}$. No hay que olvidar que en este momento histórico los recursos naturales de Hispania, sobre todo los mineros, eran ya sumamente valorados, por lo que acudían alentados por la riqueza del subsuelo hispánico numerosas expediciones ${ }^{183}$.

Con todo, la organización definitiva de la Península Ibérica se realizará bajo el mandato de Augusto, después de una etapa oscura en cuanto a las fuentes que se refieren a Hispania, seguramente debido a las luchas intestinas de Roma que provocaron una relativa falta de intervención en nuestro territorio. Aún así, sabemos de la presencia de César como próconsul de la Hispania Ulterior en el año 61, lanzando un ataque relámpago contra los lusitanos y galaicos, llegando hasta Brigantium ${ }^{184}$, y de su victoria sobre Pompeyo ${ }^{185}$, su gran rival, en el año $49^{186}$, lo que evidencia la importancia de Hispania como escenario de la guerra entre $\operatorname{los} \operatorname{dos}^{187}$.

Las guerras civiles, de Sertorio y después la de César, contra los pompeyanos causaron enormes daños en las zonas directamente afectadas por ellas ${ }^{188}$, siendo sin

${ }^{181}$ Vid. al respecto, MARÍN DÍAZ, Emigración, colonización y municipalización en la Hispania republicana, Granada, 1988, passim.

${ }^{182}$ Como sucedía, por ejemplo, en Cartago nova, a tenor de los nomina atestiguados en las inscripciones que indican la existencia de un grupo de itálicos, que seguramente constituirían un conventus en la ciudad, con peso económico y social en ella; así se aprecia en CIL II 343=2270 y 3434=2271=5027.

${ }^{183}$ Vid. al respecto, RODRÍGUEZ ENNES, Gallaecia, cit. p. 18 ss.

${ }^{184}$ Saqueando incluso las ciudades que le habían abierto las puertas, como dice Suetonio, Jul., 18, 54; Dión, 37, 52-3; Plutarco, Caes. 11-12; sobre los motivos de los ataques de César, CURCHIN, España romana, cit. p. 68: "Buscando al mismo tiempo gloria militar para continuar su carrera y botín para pagar a sus acreedores, hizo la leva de una tercera legión", atacando a continuación a los lusitanos y a los galaicos.

${ }^{185}$ Del que no hay que olvidar que fue el destinatario de la lex Trebonia del año 55, que le asignó el mando de las dos provincias hispanas durante cinco años, aunque prefirió quedarse en Italia y gobernar mediante legados.

${ }^{186}$ César, Bell. civ. 1, 37-55 y 59-87; vid. sobre su estrategia: FULLER, Julius Caesar: Man, soldier, tyrant, Londres, 1965, p. 195-206; HARMAND, “César et l'Espagne durante le second Bellum civile”, en Legio VII Gemina, León, 1970, p. 186-194.

${ }^{187}$ De hecho, lo que preocupaba a César era que, de las dos provinciae, una se hallaba estrechamente vinculada a Pompeyo, la Hispania Citerior, en donde había estado combatiendo a Sertorio desde 77-76 hasta el 72; vid. al respecto, César, Bel. Civ. 1, 29, 3-30,1.

${ }^{188}$ Vid. al respecto, una carta de Pompeyo al Senado, en la que refiere que la zona de la Hispania Citerior que no estaba en poder del enemigo -menos las ciudades del litoral- había sido arrasad bien por él, bien por Sertorio, como se recoge en Salustio, Hist., 2, 98, 9; del mismo modo, los daños causados por César fueron importantes, como se desprende de distintos testimonios arqueológicos que dan cuenta del conflicto; así, BELTRÁN, Arqueología e historia de las ciudades antiguas de Cabezo de Alcalá de Azaila (Teruel), Zaragoza, 1976. 
embargo de esta época los primeros testimonios ${ }^{189}$ de la existencia cada vez mayor ${ }^{190}$ de romanos e hispanos romanizados ${ }^{191}$. Este sería el caso de Cornelio Balbo ${ }^{192}$, nacido en Gades $^{193}$ y que había adquirido la ciudadanía gracias a Pompeyo ${ }^{194}$ durante la guerra contra Sertorio, siendo non Hispaniensis natus, sed Hispanus ${ }^{195}$.

Como señala ANDREU PINTADO196: " Sin lugar a dudas, el espacio geográfico elegido por César para difundir el Latium con mayor generosidad fue Hispania". Y esta sería la primera vez que en la historia de la República romana se integraba jurídicamente en el Estado romano a ciudades provinciales muy alejadas geográficamente de éste ${ }^{197}$.

De esta época es la ley de Urso ${ }^{198}$, Lex Ursonensis ${ }^{199}$ descubierta en Osuna ${ }^{200}$ hacia $1870^{201}$, en donde refleja en sus planchas de bronce parte de la Lex coloniae ${ }^{202}$

${ }^{189}$ FIRA I2, $n^{\circ} 36$, recoge que Cn. Pompeius Strabo concedió la ciudadanía a un grupo de caballeros hispanos, durante la campaña como cónsul en Picenum en el 89.

${ }^{190}$ Lo mismo sucede con las ciudades, aún sin estatuto jurídico alguno, pero cada vez más romanizadas; por ejemplo, Hispalis y Corduba, como se refleja en César, Bel. Civ. 2, 20, 4-5; 2, 19, 2.

${ }^{191}$ Cfr. RICHARDSON, Hispania y los romanos, cit. p. 108.

192 Vid. Vell. Pat., 2, 51.

${ }^{193}$ De la que se cuenta que César, en el año 49, concedió la ciudadanía romana a los gaditanos, y en ese momento o en los seis años siguientes alcanzó el estatus de municipium, aunque no fue nunca colonia romana; cfr. Livio, ep. 110; Dión Casio, 41, 24, 1; en este sentido, RICHARDSON, Hispania y los romanos, cit. p. 110, declara: "La concesión a Gades del estatuto de municipium fue una excepción", aunque da cuenta de la posibilidad de que Lisboa-Olisipo- también lo fuera, aunque sólo podamos deducirlo de su título municipium Olisipo Felicitas Iulia, CIL 2, 176.

${ }^{194}$ Cic. Pro Balbo, 3, 6; 22, 50-51, en donde se refleja que Pompeyo otorgó la civitas a L. Cornelio Balbo, rico ciudadano de Gades, y junto con Metelo concedió el mismo privilegio a la familia de los Fabios de Sagunto, que ya habían adoptado anteriormente nombres romanos gracias a otros contactos anteriores con miembros de familias romanas de renombre; vid. al respecto, MANSUELLI, Roma e le province, cit. p. 111: "Il primo intellettuale originario dalle provincie iberiche di cui si possa parlare è stato L. Cornelio Balbo, cittadino romano dell'antico centro punico di Gades, ma trapiantato a Roma, dove fu alla scuola di Teofane di Mitilene, lo storico di Pompeo Magno; in seguito Balbo fu tra i sostenitore di Cesare, ma in rapporti amichevoli con Cicerone, da cui fu difeso nel 56 a. C. nel processo intentatogli per usurpazione di cittadinanza, sopratutto uomo politico, non professionalmente letterato, ma colto e con interessi storici -si ricordano l'edizione di Irzio e la redazione di un diario storico".

${ }^{195}$ No siendo ciudadano romano nacido y residente en España, sino hispano.

${ }^{196}$ Edictum, Municipium y Lex: Hispania en época Flavia, Oxford, 2004, p. 7.

${ }^{197}$ Cfr. OLIVARES, Conflicto político y promoción jurídica de comunidades en el Occidente Romano (133 a. C- 174 d. C), Alicante, 1998, p. 125.

${ }^{198}$ Como afirma D’ORS, A., Epigrafía jurídica de la España romana, Madrid, 1953, p. 169: “Urso, que se identifica perfectamente con la moderna Osuna".

${ }^{199}$ Anteriormente, D’ORS se refiere a ella en un artículo, “Lex Ursonensis, capts. 107-123”, en Emerita 14, 1946, p. 24 ss.

${ }^{200}$ Aunque once pequeños fragmentos de bronce, hallados en El Rubio (cerca de Osuna), también forman parte del texto. Cfr. D’ORS, Epigrafía jurídica, cit. p. 167, en donde declara, con respecto a la fecha en la que fueron recuperados: "al parecer, en 1925. Estos fueron llamados <los bronces de El Rubio>".

${ }^{201}$ Cfr. MOMMSEN, Gesammelte Schriften I, Berlín, 1905, p. 194: “Tabulae hic editae repertae sunt a. 1870 prope Ursonem (Osuna) Baeticae".

202 Plinio, N.H. 3, 12, la cita entre las colonias inmunes del Conventus Astigitanus, con el nombre de Urso quae Genetiva Urbanorum; sobre esto último, GARCÍA Y BELLIDO, "Las colonias romanas de Hispania", cit. p. 466, cuando dice: "El cognomen de Urbanorum lo tuvo porque sus colonos fueron elegidos de entre el proletariado de la Urbs, de Roma". 
Genetivae Iuliae. Como explica D’ORS ${ }^{203}$, de César tomó “Osuna el nombre de Colonia Genetiva Iulia, en alusión a la diosa Venus Genetrix protectora de la gens Iulia a que pertenecía el dictador". Esta ley colonial ${ }^{204}$, aún siendo sospechosa de varias interpolaciones ${ }^{205}$, contiene información sustancial sobre la organización de una colonia ${ }^{206}$, iurisdictio de los magistrados (en cuyo capítulo 94 aparece una mención al imperium, que llama la atención por tratarse de magistrados municipales ${ }^{207}$ ) y uniones entre mujeres hispanas y colonos ${ }^{208}$; como dice D'ORS 209: "Los veteranos con que fundó César la colonia ciudadana de Urso debían de haber ya contraído muchos de ellos matrimonio peregrino con españolas. La ley convalida aquí tal matrimonio, declarando a tales mujeres ciudadanas, ya que las somete (legibus coloniae Genetivae Iuliae virique parento) y las beneficia (iuraque ex hac lege, quaecumque in hac lege scripta sunt, omnium rerum ex hac lege habento) con la misma condición de sus maridos ${ }^{210 "}$. Por último, hay que recordar que como consecuencia del asesinato de César, será Marco Antonio quien publique la ley definitiva en el mismo año, 44 a. $\mathrm{C}^{211}$.

\footnotetext{
${ }^{203}$ Epigrafía jurídica, cit. p. 169.

${ }^{204}$ Vid. al respecto, GARCÍA Y BELLIDO, "Las colonias romanas de Hispania", cit. p. 466: "Aunque las monedas, de comienzos del Imperio, no aluden siquiera a su condición colonial, pocas colonias estarán tan bien documentadas al respecto como la de Urso, ya que nos ha llegado buena parte de su ley constitucional, la Lex coloniae Genetivae, monumento insigne de la epigrafía jurídica romana...".

${ }^{205}$ MOMMSEN, Gessamelte Schriften, cit. p. 246: Interpolatio quatenus in has tabulas grassata sit, inde intellegetur, quod formula... cum plerumque in his ita reperiatur, ut proferri solet in prima et secunda tabula...

${ }^{206}$ Vid. al respecto, MOMMSEN, Gesammelte Schriften I, cit. p. 213: "Colonos divisos esse in tribus inde efficitur, quod magistratus creantur pro tribu $(4,18)$. Eas tribus non fuisse populi Romani, sed proprias coloniae huius vel inde intellegitur, quod Caesaris aetate uni soli ex populi Romani tribubus ut reliquarum coloniarum municipiorumque ita etiam coloniae Genetivae cives adscriptos fuisse certum et exploratum. Post reperta aera municipiorum Latini iuris Malacae et Salpensae communis opinio obtinuit res publicas formae Romanae omnes distributas fuisse curiatim; ea enim ordinatio et in illis introducta est et alibi passim observatur, maxime in Africa. Iam vero cum negari nequeat coloniam hanc a Caesare dictatore cum eam deduceret tributim ordinatam esse, accedantque tituli coloniae Augustae Lilybaei eam rem publicam duodecim tribuum fuisse declarantes, haud scio an Latinae formae rebus publicis et propterea municipiis tam propriae fuerint curiae quam tribus civium Romanorum coloniis ad ipsius Romae imaginem expressis... Ceterum curias tribusque nomine magis quam re differre et alibi demonstravi et notum est hodie pervulgatumque"; D’ORS, Epigrafía jurídica, cit. p. 231: "La colonia, al ser fundada, se distribuyó por tribus, y tal división servía para la reunión de los comicios, lo mismo que en Roma", citando la diferencia con el municipio malacitano, en el que la base de la organización es la curia, afirmando: "En realidad, la diferencia entre curias y tribus era aquí más bien nominal".

${ }^{207}$ Cfr. GRADENWITZ, en SZ 43, 1922, p. 452 ss., en donde dice que quizá sea el comienzo de una expresión que debía referirse a un verdadero magistrado cum imperium, o tal vez sea una glosa; D’ORS, Epigrafía jurídica, cit. p. 218.

${ }^{208}$ Cfr. KEAY, Roman Spain, cit. p, 56. "In 44 B.C. a group of settlers from the poorer parts of Rome were settled in a colonia within the Turdetanian settlement at Urso (modern Osuna)... This has given us an almost unique glimpse of the guide-lines which Rome laid down for the running of a colonia".

${ }^{209}$ Ibid. p. 278.

${ }^{210}$ Vid. al respecto, D'ORS, Introducción a Cicerón. Defensa del poeta Arquías, CSIC, 1940, p. 18, en donde habla de la iniciativa de César tendente a favorecer las concesiones de ciudadanía.

${ }^{211}$ MOMMSEN, Gesammelte Schriften, cit. p. 207; FERNÁNDEZ DE BUJÁN, A. , "Observaciones a propósito del tránsito de la Iberia-griega y púnica a la Hispania romana", cit. p. 28, en donde añade: "La Lex Ursonensis es la más antigua de las leges datae conocidas".
} 
A tenor de lo expuesto hasta el momento, podemos afirmar que César extendió la concesión de la ciudadanía en las dos provincias Hispanas. Como declara SHERWINWHITE"212: "Under Caesar and Augustus comes the first large-scale extension of the Roman citizenship in provincial areas ${ }^{213}$. This extension is based upon the firm foundation of a genuine Italian immigration, either of legionary veterans or of farmers, merchants, and businessmen. Beside this stands the extensive grant of ius Latii in the more Romanized areas of Spain and southern Gaul", añadiendo poco después "But the grant of civic rights to a purely native community is rare. In this respect doubtless Caesar was more lax than Augustus".

En palabras de RODRÍGUEZ ENNES'14: “Así las cosas, desde el 218 a. C. en que tuvo lugar el desembarco del ejército romano en Ampurias que inicia la presencia de Roma en Hispania, hasta el 19 a. C. en que Augusto sometió definitivamente a cántabros, astures y galaicos, transcurrieron los siglos de lenta conquista, entre incesantes guerras y rebeliones, lo que determinaría desde el principio el diverso grado de romanización existente en unas y otras regiones. Las tierras andaluzas llevaban casi dos siglos de vida pacífica bajo el influjo romano, cuando Augusto en persona y sus propios legados pugnan por reprimir los últimos levantamientos de los pueblos del Norte. Al fin la Península quedó convertida en provincia pacificada (provincia pacata)".

Nos encontramos con un nuevo período, cuyo protagonista será Augusto ${ }^{215}$, y como afirma SHERWIN WHITE"16: "The Principate of Augustus marks the opening of a new period in the history of the Roman Empire", abundando en la importancia ${ }^{217}$ de la administración provincial de Augusto. Así, en el año 27 a. C.

212 The Roman Citizenship, cit. p. 225.

213 Vid. al respecto, KEAY, Roman Spain, cit. p. 55: By the mid-first century BC, therefore, few Roman towns had been founded in Spain, and the spread of the Roman way of life was restricted to the Ebro valley, the east coast of Citerior and the greater part of Ulterior. This picture was completely transformed by the mid-first century AD. Between the deaths of Julius Caesar (44 BC) and Augustus (AD 14) legionary veterans were settled in coloniae throughout the western Mediterranean. Nine were founded in Baetica, eight in Tarraconensis and four in Lusitania".

214 Gallaecia, cit. p. 30.

215 Sobre Augusto y su obra, RICCOBONO Jr. L'opera di Augusto e lo sviluppo del diritto imperiale, Cortona, 1939, p 186: "Le guerre infatti, sotto Augusto, non mancarano. Il principale problema era di trovaree stabilire sicure frontiere per l'Impero. Restava ancora da conquistare la parte nord occidentale della Spagna, la Gallia sottomessa da Cesare in modoi incompleto, la vasta regione delle Alpi centrali ed orientali... Di tutto questo vasto programma una buona parte fu condotta a buon fine: la pacificazione della Spagna e della Gallia, per cui fu offerta ad Augusto l'Ara pacis, e poi la conquista delle regioni poste sotto il Danubio... Tale furono le imprese di Augusto".

216 The Roman citizenship, cit. p. 221.

217 Así, HARTMANN-KROMAYER, Storia romana I, trad. CECCHINI, Florencia, 1924, p. 227: "La energia guerriera e la tenacia di questo imperatores pacifico, che non andava personalmente al campo e che ha raggiunto tali resultati per mezzo dei suoi subalterni è per noi ragione di stupore e restiamo ammirati dinanzi alla conoscenza degli uomini e all'abilità con cui seppe trovare gli ausiliari che potessero portare a compimento tali imprese senza divenire mai pericolosi per lui". 
Augusto procede a realizar una nueva reorganización provincial ${ }^{218}$, dividiendo a Hispania en tres provincias: la Hispania Citerior, la Bética y la Lusitania, volcando sus mayores esfuerzos en la Citerior (llamada Tarraconensis) ${ }^{219}$.Al mismo tiempo, dirige la conquista en el año 26 a.C ${ }^{220}$. de Cantabria, Asturias y Galicia ${ }^{221}$, sin olvidar la consolidación de la política anterior de César ${ }^{222}$. Tras una victoria en el año 25 a. $\mathrm{C}^{223}$. las revueltas se sucederán ${ }^{224}$ hasta la pacificación definitiva en el año 19 a. C. Como testimonio del largo camino hasta llegar a someter completamente el territorio de Hispania, escribe Livio 225 "Aunque Hispania fue la primera provincia importante invadida por los romanos, fue la última en ser dominada completamente y ha resistido hasta nuestra época".

En la reorganización ${ }^{226}$ llevada a cabo $^{227}$, Augusto $^{228}$ decidió que la Bética se convirtiese en provincia del Senado y el pueblo, mientras que la Citerior ${ }^{229}$

${ }^{218}$ Vid. al respecto, LUZZATTO, Roma e le province, cit. p. 330: "La conquista della Galizia e delle Asturie si accompagna con la riorganizzazione della penisola, che è quindi da attribuire agli ultimi anni della permanenza di Augusto nella Spagna (27/25 a. C.). Alle due province (Spagna Citeriore e Ulteriore) del periodo repubblicano Augusto ne sostituisce tre: La Spagna Citeriore (la denominazione ufficiale rimase tale, anche se nel linguaggio corrente la provincia è talora qualificata Tarraconensis), la Lusitania e la Betica".

${ }^{219}$ Vid. sobre la intención de Augusto de consolidar la política cesariana, y su mayor esfuerzo dirigido a la Hispania Citerior, SAYAS, "Colonización y municipalización bajo César y Augusto: Bética y Lusitania", en Aspectos de la colonización y municipalización de Hispania”, Mérida, 1989, p. 40.

${ }^{220}$ Strab. 4, 18, sobre el relato de la campaña augustea.

${ }^{221}$ Sobre la denominadas guerras cántabras y su controvertida cronología: CURCHIN, España Romana, cit. p. 73 ss.; SYME, “The conquest of north-west Spain”, en Legio VII Gemina, León, 1970, p. 79 ss.; RODRÍGUEZ COLMENERO, Augusto e Hispania, Bilbao, 1979, p. 52 ss.

${ }^{222}$ Cfr. SHERWIN-WHITE, The Roman Citizenship, cit. p. 236: "Caesar and Augustus were interested in the extension rather than the limitation of privilege, Augustus maintaining what Caesar had practised on a larger scale than had been known before".

${ }^{223}$ Como se refleja en Floro, 2, 33, la fase final de la operación fue el avance en Galicia, que termina con un suicidio masivo, al modo numantino, en el monte Medulio; Suetonio, Aug. 20, 1; Dión Casio, 53, 25, 5-8; Orosio 6, 21.

${ }^{224}$ Dión Casio, 53, 29, 1-2; 54, 5, 1-3; 54, 11, 2-5; 54, $20,3$.

${ }^{225}$ Res Gestae 12.

${ }^{226}$ Como declara RODRÍGUEZ ENNES, Gallaecia, cit. p. 40: "Desde el principado de Augusto hasta comienzos del siglo III hubo, sin ningún género de dudas sólo tres provincias hispanas: la Hispania Citerior, la Lusitania y la Betica".

${ }^{227}$ Cfr. RICHARDSON, Hispania y los romanos, cit. p. 123, en donde declara que hay motivos para dudar de la veracidad de la afirmación de Dión Casio, cuando situa los cambios provinciales en el año 27 a. C.

${ }^{228}$ Original la visión que presenta WOOLF, "Provincial perspectives", en The age of Augustus, Cambridge, 2005, p. 106: "What this chapter offers is not a complementary picture of the provinces in the age of Augustus. Instead, it asks how we might write the history differently if we did not start from Rome and the first emperor", terminando por decir con respecto a la obra Res Gestae de Augusto, en p. 128: "We do not need to applaud Augustus, but it is worth following his prompt to thinking about the stage on which he performed and the script that he did not entirely write himself".

${ }^{229}$ Vid. LUZZATTO, Roma e le province, cit. p. 331, en donde aduce que las necesidades militares "spiegano la divisione della provincia in tre diocesi (Asturia et Gallaecia con due legioni; Tarraconensis con una: diocesi dell'interno) a ciascuna delle quali fu preposto un legatus Augusti con funzioni militari. Agli efetti 
(Tarraconense) y la Lusitania pasaron a ser provincias del César ${ }^{230}$, lo que supondrá en la práctica que los magistrados en la provincia senatorial ostentarán el imperium pro praetore, como subordinados del emperador, mientras que los destinados a las imperiales gozarán del imperium pro consule, como habían ostentado siempre los generales en España ${ }^{231}$. Por supuesto, continuará con la fundación de nuevas colonias $^{232}$, en una política de clara expansión del imperio Romano.

Finalmente, el emperador Vespasiano primero de los Flavios- concedió el ius latii a las tres Hispanias, una medida excepcional por su alcance, de cuya singularidad es necesario tomar conciencia ${ }^{233}$. El punto de partida lo constituye un texto de Plinio ${ }^{234}, N$. H. 3, 30, en el que nos informa de la concesión realizada por Vespasiano del Latium a Hispania:

\title{
Universae Hispaniae Vespasianus Imperator Augustus iactatum ${ }^{235}$ procellis rei publicae Latium tribuit.
}

\author{
Parece claro que nos encontramos en este pasaje con el objeto de la reforma \\ (ius latii) y con el alcance de la misma (universae Hispaniae).
}

dell'esercizio della giurisdizione la provincia è divisa nei sette conventus di Carthago Nova, Tarraco, Caesaraugusta, Clunia, Lucus Augusti, Bracaraugusta, Asturica Augusta (questi ultimi tre in Asturia)".

${ }^{230}$ Dión Casio 53, 12, 4-5.

${ }^{231}$ Vid. al respecto, MILLAR, "The emperor, the senate and the provinces", en JRS 56, 1966, p. 156-166.

${ }^{232}$ Sobre estas colonias, GARCÍA Y BELLIDO, "Las colonias romanas de Hispania”, cit. p. 474 ss. pudiendo destacar la colonia Caesar Augusta, la actual Zaragoza, fundada por Augusto hacia el año 19 a. C. con veteranos de diversas legiones, como la X Gemina, que habían tomado parte en las guerras cántabras, y, como dice el autor en p. 484: "Quizá aún en curso cuando la fundación, pues la fecha de ésta no es del todo segura"; Quizás la más reconocida sea la colonia Augusta Emérita, que se corresponde con la Mérida actual, citada en Strab. 3, 2, 15, ya como colonia, juntamente con Caesar Augusta; cabeza del conventus de su nombre, como señala Plin. N. H. 4, 117, debió de ocupar una gran superficie; como señala García y Bellido en p. 488: "Aunque no sea posible fijar con precisión los límites de este territorio colonial sí es hacedero formsrse una idea aproximada de su enorme extensión”, recordando a continuación que uno de los motivos de la fundación de esta colonia fue para reforzar la defensa de esta parte de la Lusitania.

${ }^{233}$ Cfr. ANDREU PINTADO, Edictum, Municipium y Lex, cit. p. IX.

${ }^{234}$ Que toman como referencia: MCELDERRY, "Vespasian's Reconstruction of Spain", en JRS 8, 1918, p. 62-68, en donde comienza por el texto pliniano, y MONTENEGRO, "Problemas y nuevas perspectivas en el estudio de la Hispania de Vespasiano", en H. Ant. 5, 1977, p. 7-13, en donde destaca de igual modo el texto de Plinio.

${ }^{235}$ Existe debate sobre este término, primero sobre cuestiones filológicas, sobre si la lectura debe ser iactatum o iactatus, y sobre las que se pronuncia ZECCHINI, "Plinio il Vecchio e la Lex Flavia municipalis", en ZPE, 84, 1990, p. 14, diciendo que leer iactatus supone elegir una lectio facilior no justificada, ya que de cinco códices que se conservan de Plinio, tan sólo dos presentan dicha variante; segundo, se cuestiona desde un punto de vista histórico la acepción de este término, como RICHARDSON, The Romans in Spain, cit. p. 191, que ha leido iactatae refiriendo a Hispania dicho adjetivo, queriendo ver en las palabras de Plinio una referencia a una Hispania devastada, incluso en el plano sicológico, debido a la guerra civil del 68-69 d. C. 
Lo que supone la concesión del ius latii es destacado por GONZÁLEZ, $\mathrm{J}^{236}$. al señalar que en las provincias más romanizadas, a la extensión del ius latii seguía normalmente la mejora del estatuto jurídico de las comunidades y la aparición de municipia Latina ${ }^{237}$, y ello ha provocado que la investigación sobre la naturaleza y el contenido esencial del ius Latii se divida entre los que defienden el Gemeinderecht ${ }^{238}$, el carácter del ius latii como derecho de comunidades, y los partidarios del Personalrecht ${ }^{239}$, que entienden el ius latii como un derecho personal. Estas diferentes posturas han procurado un encendido debate en los últimos tiempos ${ }^{240}$, aún cuando se vislumbre alguna postura de carácter conciliador en medio de algunos de los que defienden el carácter o no personal de dicho derecho.

Resumo: O presente artigo analisa desde os motivos que levaram os romanos a conquistarem o território espanhol, até o evento políticosocial sobre a organização romana transposta para aquele lugar, conforme a evolução do conceito de provincia. Por fim, destaca-se a importância das leis municipais, detendo-se na concessão do ius latti por parte do imperador Vespasiano.

Palavras-chave: Provincia. Hispania. Município. Ius latii.

236 "Las leyes municipales Flavias", en Aspectos de la colonización y municipalización de Hispania, Mérida, 1989, p. 143.

237 Vid. al respecto, GARCÍA FERNÁNDEZ, El municipio latino. Origen y desarrollo constitucional, Madrid, 2001, passim.

${ }^{238}$ Vid. entre los que participan de esta tesis: MOMMSEN, "Die StadRechte der Lateinischen Gemeinden Salpensa und Malaca in der Provinz Baetica", en Iuristische Schriften I, Berlín, 1905, p. 265-382, primero en concluir que el privilegio del Latium sólo podía ser referido a una comunidad, negando que pudiese existir una idea abstracta de ciudadanía latina supraterritorial; GALSTERER, Untersuchungen zum Römischen Städtwesen auf der Iberischen Halbinsel, Berlín, 1971, p. 40, en donde señala que del CIL II, 1610, 1049, 1050, 2322, 2477, 5217, se desprende la idea del valor colectivo del Latium, ya que en dichos documentos la condición de civis Latinus sólo aparece en plural; WOLFF, "Kriterien für latinische und römische städte in Gallien und Germanien und die 'Verfassung' der gallischen Stammesgemeinden", en Bonner Jahrbücher, 176, 1976, p. 52, 57 y 77, insistiendo en que las referencias contenidas en las leges municipales con respecto a la forma de desenvolverse los Latini en comunidad (x. ej. Cap. 21-23 y 29 de la Lex Salpensana) prueban que dicha condición sólo podría existir dentro de la misma; GARCíA FERNÁNDEZ, El municipio latino, cit. p. 129.

239 Como MILLAR, The Emperor in the Roman World (31 BC.- 337 AD.), 1977, p. 398, que habla de una vinculación entre el ius latii y la concesión individual de la civitas per honorem, afirmando que el ius latii era el único sistema que permitía a los peregrini entrar a formar parte del ordenamiento romano a través del puente hacia la civitas romana que el Latium suponía; otros inciden más en la innecesaria correspondencia entre la concesión del Latium y la promoción estatutaria de una comunidad, como SHERWIN-WHITE, The Roman Citizenship, cit. p. 362, en relación con la Gallia Cisalpina; GALSTERER-KRÖLL, "Zum ius latii in des Keltischen Provinzen des Imperium Romanum", en Chiron 3, p. 305-306, en relación con la Céltica, concluyendo que en estos casos no siguió al Latium la municipalización.

${ }^{240}$ Cfr. MENTXAKA, El Senado municipal en la Bética hispana a la luz de la Lex Irnitana, Vitoria, 1993, p. 41-44, en donde refiere un resumen de dicho debate, con una serie bibliográfica. 